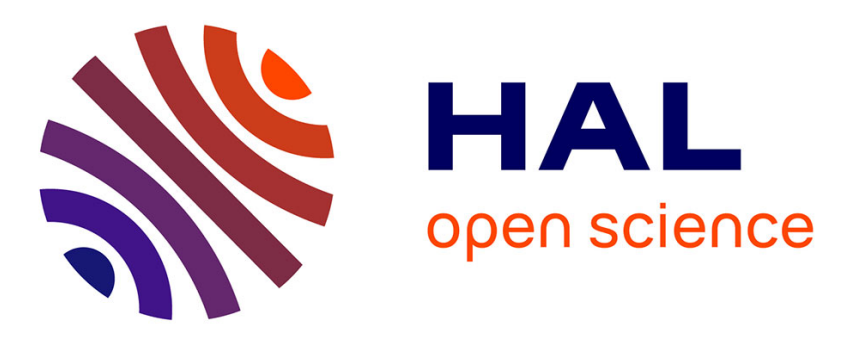

\title{
Relational Capability: A Multidimensional Approach
}

Gaël Giraud, Cécile Renouard, Hélène L'Huillier, Raphaële de La Martinière, Camille Sutter

\section{To cite this version:}

Gaël Giraud, Cécile Renouard, Hélène L'Huillier, Raphaële de La Martinière, Camille Sutter. Relational Capability: A Multidimensional Approach. 2012. halshs-00827690

\section{HAL Id: halshs-00827690 \\ https://shs.hal.science/halshs-00827690}

Submitted on 29 May 2013

HAL is a multi-disciplinary open access archive for the deposit and dissemination of scientific research documents, whether they are published or not. The documents may come from teaching and research institutions in France or abroad, or from public or private research centers.
L'archive ouverte pluridisciplinaire HAL, est destinée au dépôt et à la diffusion de documents scientifiques de niveau recherche, publiés ou non, émanant des établissements d'enseignement et de recherche français ou étrangers, des laboratoires publics ou privés. 


\section{Documents de Travail du Centre d'Economie de la Sorbonne}

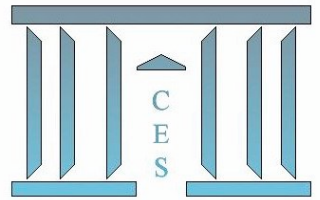

\section{Relational Capability: A Multidimensional Approach}

Gaël GIRAUD, Cécile RENOUARD, Hélène L'HUILLIER, Raphaële de la MARTINIÈRE, Camille SUTTER

2012.96

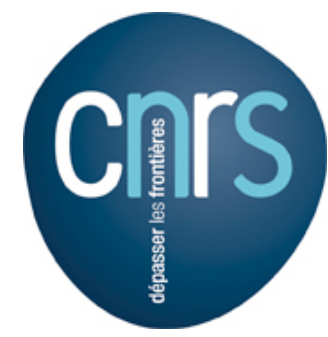




\title{
Relational Capability: A Multidimensional Approach
}

\author{
Gaël Giraud, Cécile Renouard ${ }^{\dagger}$ \\ Hélène L'Huillier $\ddagger$ Raphaële de la Martinière, Camille Sutter?
}

14 December 2012

"The purpose of development is to offer people more options. One of their options is access to income - not as an end in itself but as a means to acquiring human well-being. But there are other options as well, including long life, knowledge, political freedom, personal security, community participation and guaranteed human rights. People cannot be reduced to a single dimension as economic creature." UNDP, Human Development Report, 1990

\section{Abstract}

This paper explores some of the dimensions related to poverty and exclusion, by defining a Relational Capability Index (RCI) which focuses on the quality of relationships among people and on their level of relational empowerment. This index is rooted in a relational anthropology; it insists on the quality of the social fabric and of interpersonal relations as a key aspect of human development. As a multidimensional index, the RCI includes integration into networks, private relations and civic commitments. We provide an axiomatization of a family of multidimensional indexes. This axiomatic viewpoint fills the gap between theories of justice and poverty measurements. By means of illustration, we apply three different versions of the RCI, which are elements of this family, to the measurement of the impact of oil companies on local communities in the Niger Delta (Nigeria) and to national surveys (Afrobarometer).

${ }^{*}$ CNRS, Centre d'Economie de la Sorbonne, Paris School of Economics.

${ }^{\dagger}$ ESSEC Business School, Companies and Development (CODEV), renouard@essec.edu

${ }^{\ddagger}$ ESSEC, CODEV.

$\S$ ESSEC.

"ENSAE ParisTech. 


\section{Introduction}

This paper contributes, both theoretically and empirically, to the measurement of multidimensional aspects of development. This line of inquiry has been initiated by Amartya Sen (Sen, 1999) and expanded by the UNDP (Human Development Report), the Human Development and Capability Association and the Oxford Poverty and Development Initiative (OPHI). In 2010, the OPHI and UNDP introduced a Multidimensional Poverty Index which entails three components: health, education, and living standards ${ }^{1}$ The justification for the choice of these components is threefold: the areas are of key importance in terms of human development and Millenium Development Goals; a consensus has been reached on the importance of these components from a practical perspective (thanks to a participative methodology) and from a theoretical one (universal recognition of health, education and living conditions as core dimensions of human rights); and there are several data constraints facing the field. The initiators of this index, however, underline the importance of focusing on other human capabilities as well. Alkire and Santos (2010), for instance, emphasize that "a key priority for future work on multidimensional poverty must be gathering more and better data around core areas such as informal work, empowerment, safety from violence, and human relationship (social capital and respect versus humiliation). This will enable empirical exploration of whether such dimensions add value to a multidimensional poverty measure." The present paper explores some of these later dimensions, by defining a new index - the Relational Capability Indexwhich focuses on the quality of relationships among people and on their level of relational empowerment. We discuss the philosophical roots of such a measurement concept, as well as its methodological challenges. As an illustration, we apply this index to measuring the impact of oil companies on local communities in the Niger Delta (Nigeria), and to national surveys (Afrobarometer).

Our perspective is rooted in a specific understanding of human development through the expansion of (individual) capabilities to share flourishing relationships. Human relationships are at the core of human life - this is the starting point of our work. Arguably, emphasizing, as we do, the relational aspect of social life amounts to adopting a normative standpoint about what makes our lives "human". We shall see, however, that such a prejudice is in line with, for instance, the recent work by Nussbaum. On the other hand, however, we put the accent on capabilities, i.e., on "what people are actually able to do and to be" (De Munck and Zimmermann, 2008, Nussbaum, 2003), including access to resources, agency (capacity to make free choices), and functionings (achievements). Our approach therefore puts social networks at the center of the very concept of human development but, at the same time, acknowledges the diversity of personal and collective values and ends. In particular, we refrain from imposing a single view of what it should mean to have flourishing relationships. This is reflected in the specific methodology we develop in order to aggregate the various dimensions of our index into a single real number.

\footnotetext{
${ }^{1}$ See Alkire and Foster (2008), Alkire and Santos (2010) and UNDP 2010).
} 
The paper proceeds as follows. We first present our relational approach based on individual capabilities in view of the various concepts of social development already examined in the literature (2). The following section then proposes a set of dimensions and indicators entering into the construction of ourRCI, and proceeds with the aggregation of such dimensions into the RCI, as partly inspired by the Multidimensional Poverty Index methodology (cutoffs, means, and weights) (3). Section 4 details the axiomatic model that justifies the way the index dimensions have been aggregated, and the index's properties. The last section presents two empirical applications (5). The case of areas impacted by oil extraction in the Niger Delta, in Nigeria, illustrates the practical relevance of the RCI. Its computation at a national level by means of the Afrobarometer shows that our index is intuitive, simple to use, and can be applied with good effect to real-world data.

\section{Concepts - towards a relational development}

Today's definitions of poverty are often framed in terms of the (lack of) capacity of a person to participate in the society in which they live. For instance, the notions of social inclusion, social integration or participation have become widespread in international institutions such as UNDP or the World Bank. Similarly, the World Summit for Social Development in Copenhagen in 1995 (Marlier and Atkinson, 2010) describes the "process by which efforts are made to ensure equal opportunities - that everyone, regardless of their background, can achieve their full potential in life." The goals of social integration and inclusive society depict "a more stable, safe and just society for all", in which every individual, each with rights and responsibilities, has an active role to play" (United Nations, 1995, par 66).

This approach in terms of social inclusion is a significant step towards a more satisfactory understanding of poverty, as opposed to the definitions relating to financial and real assets that were previously prevailing. It enables a view of poverty as a complex set of deprivations: malnutrition and bad health, lack of access to the job market, low mobility, low social capital, low skills and incomplete education, etc.

However, viewing poverty as a lack of social inclusion is not immune to ambiguity. For instance, the World Bank's "Poverty Reduction Strategy" and the Post-Washington Consensus claim that their aim is to ensure everybody is able to participate in the market economy (which is seen as an opportunity to overcome poverty); such a purpose rarely involves any criticism of the deadlocks of this deregulated market economy, and only (monetary) compensations of the negative side effects of structural adjustments are envisioned. Moreover, most recommendations are phrased as if there was an implicit discipline of integration, a "duty" to accept the programs under scrutiny: the poor who do not seize the opportunities on offered might even be sanctioned, inasmuch they will suffer from a moral stigmatization of being the "lazy poor." Finally, within this context, the idea of social development is usually linked with the search for social investments (human and social capital); it is about competitive societies and integrated national economies.

Consequently, this understanding of poverty often leads to the idea that poverty re- 
duces to a lack of social capital - where "social capital" is "a variety of different notions that have two elements in common: [...] all consist[ing] of some aspect of social structures, and facilitate[ing] certain actions of actors - whether persons or corporate actors - within the structure" (Coleman, 1988). Both Bourdieu (1994) and Coleman (1988) consider social capital as relational resources which can be accumulated over a lifetime through various "social investments", and give access to goods or opportunities. In our view, this approach has two main limits. First, it is a "capitalist" approach (accumulation as an advantage "against" other people) which shows a very partial aspect of social connectedness, inasmuch as it is blind to the positive externality implied by socialization. Second, this instrumental approach cannot seize social relationships as an accomplishment and a goal for itself.

\subsection{Social connectedness as a public good}

Beyond the ethical criticisms, the social capital approach does not allow for a full comprehension of the functioning and outcomes of social interconnection. Representing it as a (rare and) valuable resource overshadows its principal characteristic as a public good: its capacity to be shared without impoverishing its "owner" (like knowledge). Therefore, our approach is closely related to the traditional view of social capital as being the positive effect of social closure - i.e., the presence of cohesive ties - in promoting a normative environment that facilitates trust and cooperation between actors (Coleman (1990, 1988)). As stressed by Coleman (1988, p.119), "a property shared by most forms of social capital that differentiates it from other forms of capital is its public good aspect: the actor or actors who generate social capital ordinarily capture only a small part of its benefits, a fact that leads to underinvestment in social capital." It is this public good aspect that we aim to capture, as we suggest that the relational payoff of an actor must depend not only upon the number of neighbors they have, but also upon their respective connectedness with these neighbors.

This means, in particular, that producing and consuming goods and services should be viewed as a means towards the maximization of people's relational capability. This is evident - and has already been acknowledged by economists - for club commodities (Ellickson et al. (1999, 2001)); i.e. for commodities whose value increases with the number of people connected to them (such as the phone, Internet, Wikipedia, Google, Facebook, Second Life, etc.). For instance, if Robinson Crusoe were the only person on Earth to own a phone, the phone would be useless; yet if he can talk with 6 billion people, the value of his phone becomes almost infinite. In a sense, our approach amounts to saying that most commodities and services share the same fundamental property as club commodities: Their value arises from the quantity and the quality of the relationships that their consumption makes possible, as well as from the richness of the relationships that were necessary to produce them. Most people do not watch TV "because" TV programs are intrinsically interesting, but "because" it is a way to enter into relationships with people who have watched the same programs (hence allowing them to share the same information about the world, dream about the same "Californian way of life," etc.). Think about it: would you even listen to Monteverdi, read Hegel or admire Turners' 
masterpieces if you were absolutely sure that nobody cared about them and nobody ever would? Of course, there are exceptions: even before meeting Friday, Robinson Crusoe needs some basic items in order to survive on his island - non-polluted oxygen, drinkable water, vitamins, natural sunlight, etc. Let us call these "basic goods." Our viewpoint is therefore that, apart from a few basic goods (whose list should be fixed and from which many people in the world are still deprived), all commodities and services are "club goods" (or "club bads"). Some examples may facilitate understanding of this renewed approach: for instance, "blood diamonds," whose production has lead to a war in Sierra Leone and the exploitation of children, should have a negative value regardless of the subsequent use rich Northern households make of them. Conversely, "fair trade" can be viewed as a (still ambiguous) first step towards the integration of relational capability into the price of marketed commodities, where consumers buy coffee not only "because" of its "intrinsic taste" (which, from our viewpoint, is closely related to the relationships entertained during the time spent, for instance, at breakfast, when drinking coffee with family) but "because," by doing so, they learn the story of the Columbian producer of coffee whom they choose to sustain. Numerous situations are quite ambivalent and need a close analysis: an activity such as tourism, for instance, indicates, at first glance, the triumph of relationships over the narcissistic pleasure of consuming commodities. On the other hand, sexual tourism, such as that in South-East Asia, shows that "touristic relationships" may induce major deprivations. Obviously, this approach leads us far away from the libertarian Weltanschauung claiming that everything that receives a "free price" ipso facto becomes a legitimate market commodity. In particular, it leads us to consider the idea that markets and private contracts should be re-embedded within their surrounding society (Polanyi, 1957; Porter and Craig, 2004).

\subsection{Social cohesion}

In line with the Polanyian criticism of the above-described inclusive liberal society, the notion of social cohesion states that "a socially cohesive society is one where all groups have a sense of belonging, participation, inclusion, recognition and legitimacy."

According to Bernard (1999), social cohesion entails a set of relationships in economic, political and socio-cultural spheres at the same time. These relations are can be of two kinds: formal relationships define the passive integration of people in a society through access to resources, integration into networks, and rights and entitlements. These are what Sen calls "resources" and "entitlements" (Sen, 1999). On the other hand, substantial relations define the active commitment of individuals in social interactions that express achievements of their capabilities. This is what Sen calls "functionings".

From the perspective of the capability approach, to which this paper adheres, we can refine Bernard's typology of social cohesion. 


\begin{tabular}{|l|l|l|}
\hline Domains & $\begin{array}{l}\text { Formal relationships : } \\
\text { Resources; } \\
\text { Passive integration into networks; } \\
\text { Rights and entitlements. }\end{array}$ & $\begin{array}{l}\text { Substantial relationships : } \\
\text { Commitment in relationships; } \\
\text { Functionings. }\end{array}$ \\
\hline $\begin{array}{l}\text { Economic } \\
\text { or Material }\end{array}$ & $\begin{array}{l}\text { Insertion/Exclusion } \\
\text { Relational assets; } \\
\text { Access to market, jobs; } \\
\text { Access to infrastructures and public } \\
\text { services (health, education); }\end{array}$ & $\begin{array}{l}\text { Equality/Inequality } \\
\text { Equality in chance and equality in } \\
\text { conditions: effective redistribution system, } \\
\text { social mobility. }\end{array}$ \\
& $\begin{array}{l}\text { Access to social services. } \\
\text { Socceptance/Rejection }\end{array}$ & \\
& $\begin{array}{l}\text { Equality in rights; } \\
\text { Non-discrimination; } \\
\text { Tolerance in differences, pluralism. }\end{array}$ & $\begin{array}{l}\text { Affiliation/Isolation } \\
\text { Social interactions, love, friendship; } \\
\text { Share of common values; } \\
\text { Trust, feeling of belonging to a community } \\
\text { (as opposed to social isolation). }\end{array}$ \\
\hline Political & $\begin{array}{l}\text { Legitimacy/Illegitimacy } \\
\text { Maintenance of public and private } \\
\text { institutions acting as mediators } \\
\text { (as opposed to social chaos); } \\
\text { Political rights (vote, meeting, expression); } \\
\text { Trust in institutions. }\end{array}$ & $\begin{array}{l}\text { Participation/Passivity } \\
\text { Involvement in public affairs and/or third sector; } \\
\text { Vote (as opposed to political disenchantment). }\end{array}$ \\
\end{tabular}

Table 1: Dimensions of social cohesion (Bernard 1999) from the perspective of the Relational Capability Approach

Social cohesion creates conditions for better interpersonal, as well as mediated relations, within a society (Kuehnast and Dudwick, 2004). Several surveys have recently highlighted the tight relationship between the level of income inequalities within countries and the level of social and health problems. Wilkinson and Pickett (2009) show that huge inequalities (such as those experienced today in many industrialized countries) have negative side effects for the whole population (not only for the poorest) in terms of sanitation and social diseases. In addition, the richest people across all countries are also those who pollute more and bear a huge responsibility towards future generations (Giraud and Renouard, 2012). As a consequence, there is a link between fostering relational capabilities, and public and private policies aimed at reducing wealth inequalities.

This discussion suggests that our relational capability approach entails not only "formal" aspects, in the Rawlsian sense (Rawls, 1971) of aspects that can be discussed without having to agree on any substantial definition of the "common good," if any. Clearly, our emphasis on human relations also involves substantial aspects, which have to be grounded in some underlying anthropology - to which we now turn.

\subsection{A relational anthropology}

Each development indicator is underpinned by a certain conception of the human condition and of what a "good life" means. We defend a perspective that stresses the essentially relational and social nature of every person. A flourishing life, in this regard, 
is a life that enables a person to develop fruitful relations with themselves and with their fellow human beings in a given political community. Development is then understood above all as a matter of fostering the conditions for such a flourishing life. This does not mean that basic material needs and income fall outside the scope of our understanding of development: rather, they are incorporated as means towards people's relational capability.

Let us first contrast this standpoint with the utilitarian tradition before turning to a discussion of the relationships between our relational capability approach, and that of Nussbaum 20002.

\subsubsection{Utilitarianism and beyond}

Utilitarianism is a philosophical line of thought whose aim was defined by Bentham (1815) as maximizing the utility or happiness of the greatest possible number of people. It has had many important consequences on reflections about morality: it is a consequentialist perspective which focuses on the outcomes of an action, and has little regard for its intentions. Can we find some intellectual resources within the utilitarian school of thought which would enable it to counter the maximization of personal utility and the sacrifice of the freedoms and capabilities of the most vulnerable? Indeed, such an internal criticism has been made by John Stuart Mill (1861), who developed his own account of utilitarianism.

Not only does Mill leave the possibility of altruism open, but he even defines utilitarian ethics as the effort to shape people's altruism and to find happiness within it, "so that not only may he be unable to conceive the possibility of happiness to himself, consistently with conduct opposed to the general good, but also that a direct impulse to promote the general good may be in every individual one of the habitual motives of action, and the sentiments connected therewith may fill a large and prominent place in every human being's sentient existence" (Mill, 1861, chpt.2). Relationship to others is essential for Mill. His arguments consist in emphasizing the importance of education to instill in one's character the feeling of being united to one's fellow human beings. What shapes a society is the importance and the nature of the bonds between people. Human progress is rooted in the strengthening of social bonds and the care for the others' interests. Even more, the challenge is to help people discover that looking for the good of others is a source of personal flourishing and happiness. Virtue has to become desirable, if understood as the personal development of intellectual and moral abilities and being linked with the search for the good of others and for the common good. Nevertheless, aside from this self-detachment and this impetus toward the common good, establishing safeguards, through external legal constraints, regulations and sanctions, is necessary in order to guarantee the realization of common interests.

Mill fights against a utilitarian conception centered on the maximization of individual pleasures, while refusing a moral perspective sacrificing sensible inclinations. The idea is

\footnotetext{
${ }^{2}$ An expanded version of this analysis is presented in Renouard (2011)
} 
to orient the individual desire towards the care of others, so that the search for personal happiness and the quest for the good of others merge. Mill stresses that the highest level of self-fulfillment and happiness is reached when relating to others. "The utilitarian morality does recognize in human beings the power of sacrificing their own greatest good for the good of others. It only refuses to admit that the sacrifice is itself a good [...] The only self-renunciation that it applauds, is devotion to the happiness, or to some of the means of happiness, of others" (Mill, 1861, chpt.2). This is not to be interpreted as the possibility of sacrificing the least productive people. Mill argues in favor of the education of every citizen, and in particular of the elites, for the well being of others, and for the eradication of poverty. In this regard, Mill's view joins the Kantian perspective, according to which morality encompasses a disinterested relationship with others (Kant, 1785). However, Mill takes into account human psychology: the aim is not a total selfrenunciation of the individual, but his fulfillment in the care of both the others' good and the common good. Finally, relational anthropology defines human relationships as the substance of human identity: being is relational and a flourishing human life is experienced in autonomy and interdependence.

\subsubsection{Relational autonomy and interdependence}

Relational anthropology focuses on the relational capabilities of each person as constituting the core of human condition. The link between the individual and the collective can be elucidated in the sense that defining a person through the quality of the relations they have with other human beings does not mean that the individual is denied their autonomy and freedom of choice. We combine a relational ontology, which refuses on considering the human being as an isolated atom, with an ethical individualism, which recognizes the moral responsibility of each person. Indeed, as acknowledged by Dreze and Sen (2002, p.6) or Robeyns (2005, p.108), "A commitment to ethical individualism is not incompatible with an ontology that recognizes the connections between people, their social relations, and their social embedment." We call "relational autonomy" this combination of a relational ontology and an ethical individualism. Our relational starting point means that, like Marion Young (Young, 2000, p.231), we depart from an understanding of freedom as mere independence and non-interference. But our ethical individualism forces us to go beyond Young's social ideal, which consists of shaping all kinds of relations, within the family as well as within society, so as to allow each individual to maximize their private goals. In contrast, relational autonomy means that everybody is invited to contribute to some common goals that can, in turn, affect their individual objectives.

\subsection{Relationships and the capabilities approach}

Our perspective is rooted in a liberal view, which stresses the freedoms and rights of each individual. In this regard, we focus on the capabilities, rather than the functionings, of each citizen. Following Sen, we argue that every society has to enable each individual to make choices she has reasons to value (Sen, 1999). As shown above, we put an 
emphasis on the social condition of every person. We combine this liberal perspective with an Aristotelian standpoint that gives an account of substantial aspects of human development Aristotle (50BC).

Our relational capability brings together several dimensions necessary for a flourishing human life from the list of central capabilities given by Nussbaum (Nussbaum, 2000), among which are emotions and affiliation. Emotions and affiliation are defined as follows:

- Emotion: "Being able to have attachments to things and people outside ourselves; to love those who love and care for us, to grieve at their absence; in general, to love, to grieve, to experience longing, gratitude, and justified anger. Not having one's emotional development blighted by overwhelming fear and anxiety, or by traumatic events of abuse or neglect. (Supporting this capability means supporting forms of human association that can be shown to be crucial in their development.)"

- Affiliation: "Being able to live with and toward others, to recognize and show concern for other human beings, to engage in various forms of social interaction; to be able to imagine the situation of another and to have compassion for that situation; to have the capability for both justice and friendship. (Protecting this capability means protecting institutions that constitute and nourish such forms of affiliation, and also protecting the freedom of assembly and political speech.)"

Two ideas advocated by Nussbaum are of major importance regarding relational capability: her invitation to let public policy focus on the capabilities of individuals and not on their functionings; and her emphasis on affiliation (Nussbaum, 2002, p.134). The present definition of relational capability complements Nussbaum's attempt to define a "politics of care" in three different ways: first, we give priority to relational capability as being the core of a truly human life. Thus, we follow Sen in his emphasis on freedom, but freedom is understood, here, as autonomy and interdependence $3^{3}$ Secondly, the personal dimension (the immediate relationship to others as fellow human beings) is linked with the political/civic dimension (the mediated relationship to others as socii through institutions). On the one hand, any human being is immediately embedded in, and partly shaped by, their political society. Conversely, interpersonal relations contribute to transforming political rules and structures. Thirdly, we aim to capture the capability to form relationships within a group (bonding) and between groups (bridging). Bonding deals with social cohesion and with the implementation of a complex equality (Walzer) between citizens of a same political community or the same company. Bridging entails the consideration of relations between different citizens or groups from different communities or states.

\footnotetext{
${ }^{3}$ This understanding of freedom is in accordance with Nussbaum (2003, p.44) where it is stressed that the capability approach implies limiting certain freedoms for certain people in order to diminish inequalities in capacity.
} 


\subsection{Bonding and bridging}

Burt (1997, p.340) defines social capital as the "information and control advantages of being the broker in relations between people otherwise disconnected in social structure." This structural hole argument is reflected, here, in our definition of an actor's relational payoff, inasmuch as this payoff increases together with the density of the various otherwise-disconnected components of the social network that an actor is able to link together. We do not restrict social capital to brokerage opportunities: doing so would lead an actor to overevaluate links with disconnected people while, here, an actor also benefits from the various relationships among her neighbors. The same could be said from Granovetter's (1985) understanding of social capital in terms of weak ties: if one interprets such "weak ties" as links among components that are otherwise poorly interconnected, then, again, this feature is captured by the $\mathrm{RC}$, but reflects only one aspect of the richness of the relational payoff.

On the other hand, we do not share Coleman's (1988) final pessimism over the underinvestment in social capital. On the contrary, our starting point is to hypothesize that most people's behavior can be understood as seeking to maximize something akin to the relational payoff. Moreover, Coleman claims (Coleman, 1988, p.101) that "the function identified by the concept of social capital is the value of these aspects of social structure to actors as resources that they can use to achieve their interests." Again, we do not agree with this instrumentalist point of view in the sense that, according to the position adopted in this paper, relationships are not considered by an actor as an auxiliary means to serve exogenous goals: creating and maintaining relationships within a dense network of neighbors is the actor's goal, with respect to which everything else (commodities, money, power, etc.) should serve as an instrument.

Burt (1992) has challenged the widespread idea that societies belonging to a denser network should experience faster development: this can be illustrated by the idea of a tribe of people, living on an isolated island, entirely disconnected from the rest of the world. Burt has thus suggested that "structural holes" should play a role in transmitting new ideas or new ways of life, so that their frequency should serve as a criterion of the ability of a group to experience development. Our opinion is that, behind this debate, there are two, partly contradictory, anthropological pictures: on the one hand, a rather "communitarian" viewpoint will tend to favor the density (and quality) of relationships within one's immediate neighborhood; on the other hand, a more "libertarian" point of view will tend to put the accent on the competition among individuals, and hence on the ability of an agent to grasp new information from various sources with whom the individual does not aim to entertain strong, intense relationships.

Our own understanding of relational capability lies somewhere in between both approaches. Indeed, adopting Burt's approach in a unilateral way would neglect the densityquality of networks: "structural holes" can be useful only if they make it possible to connect two, perhaps far distant but otherwise highly dense, small worlds. This is why we distinguish between several levels of relationships - integration into social networks, private relations, political commitments (see the three pillars of subsection 2.6.1 below). 


\subsection{Political perspectives}

\subsubsection{RC and its three pillars}

We distinguish three different dimensions of relational capabilities: the ability to be integrated into networks; private ties; and civic commitments. Each dimension deals with a different kind of possible inclusion/exclusion within a society. Building on the distinction between economic, cultural and political aspects of social cohesion (Bernard, 1999) and justice (Fraser, 2009), we now show that each of the dimensions of relational capability implies the consideration of a certain type of inclusion. The first dimension of exclusion is socio-economic, and can be related to our first dimension-integration into networks: this can be illustrated by the idea of somebody who has no job and who has little access to information and to transport, and is thus deprived and somehow excluded from relational material networks. Looking for the improvement of this first socio-economic dimension means looking for a better distribution of relational assets, as well as job opportunities and transportation means. The second dimension of exclusion is cultural/social, and corresponds to our second dimension - private relations: for instance, a person who feels that they are not loved by their family, who has no friends or who cannot rely on others in case of trouble, is socially excluded. This has to do with the lack of recognition and with the isolation they experience. A condition for the inclusion of a person consists in their social and cultural recognition. The third dimension of exclusion is political, and links to our third dimension - civic commitments. A person who cannot vote and who cannot take part in their community/society life is suffering from discrimination and a lack of control over their political destiny. A key issue related to civic inclusion is the ability to participate in social and public life, or to be represented at different political levels.

On the one hand, our index builds on Nussbaum's perspective concerning central capabilities: by adopting cut-offs below which an individual is considered as deprived, we implicitly defend the idea that a certain minimum threshold has to be looked for in each dimension of one's social life. However, we stress the idea, which was well expressed by Walzer (1983), that a condition for self respect is the recognition of a person in at least one sphere of their existence. This will be reflected in the way in which we aggregate the three pillars of the RCI.

\subsubsection{Can we compare relational capabilities?}

Measuring and comparing relational capabilities across countries faces an obvious criticism: as the criteria for high-quality relations will vary a great deal between cultures, is it possible and legitimate to compare them? There are four reasons why we find such comparisons legitimate, despite their obvious methodological challenges:

Firstly, we have defined relational capabilities as having a link with a relational ontology that has a universal perspective. We argue that a human life is human because of the ability to form positive relationships with fellow human beings and with the cosmos, in the context of a given society. Even though the content given to the equality of 
these relations will vary across cultures, we can defend a thin universalism (Walzer. 1994) that combines the uniqueness of every person and their interdependency with others. Defining the relational identity of a person consists in refusing both solipsism and collectivism. As stated above, we plead for a combination of relational anthropology and ethical individualism.

Secondly, we define three components which are subject to basic formal agreement across cultures, through an overlapping consensus (Nussbaum, 2000; Rawls, 1971). Moreover, as we focus on capabilities, rather than functionings, as a political goal, we do not impose a single way of implementing relational capabilities; we only suggest that every human being has to be entitled to be integrated into networks, to nurture rich private relations and to take part in civic life.

Thirdly, the way in which we calculate the RCI gives all the more weight to a dimension than a person is better off in it. This is in line with Walzer's suggestion of a justice criterion for our complex and pluralist societies: the objective consists of attaining societies in which all citizens have self-respect; this stems from self-esteem, which is achieved through the recognition of every person in a given sphere of life.

One characteristic of unfair societies is the domination of a small group of people in all spheres. Nevertheless, Walzer does not take into account the criteria for a fair distribution of goods in every sphere. As far as relational capabilities are concerned, we defend the idea that each person should be entitled to a minimum in terms of access to networks, private relations and civic commitments; in this regard, we endorse the threshold perspective defended by Nussbaum. But we also defend the Walzerian idea that the components are partially substitutable. As a consequence, we do not claim that all the spheres always have, or ought to have, the same weight across cultures.

Fourthly, we promote a diachronic analysis which pays particular attention to the compared evolution of and between countries. In this sense, we are less interested in the static comparison between different contexts than on the ways in which situations evolve.

\section{Dimensions and indicators of relational capability}

\subsection{Constructing a multidimensional poverty index}

Two distinct approaches of index methodology can be found in the literature. One is related to the normative construction of indexes, the second is related to data-driven indexes. Normative indexes are theoretically based and do not depend on the data considered. Data-driven indexes are computed according to the statistical significance of components.

A normative computation of indexes is the most frequently used within multidimensional approaches to poverty. A large body of literature has been inspired by the AlkireFoster method (Alkire and Foster, 2008) 4 . It consists of an arithmetical aggregation of

\footnotetext{
${ }^{4}$ See, for instance, Alkire and Seth (2008), Santos and Ura (2008), and Batana (2008) computing multidimensional poverty index (MPI), and UNDP Europe \& CIS (2011) computing a multidimensional social exclusion index.
} 
three dimensions of poverty that are theoretically defined. Each dimension is an equallyweighted average of components, and is also equally weighted in the index computation. Each component represents one aspect of deprivation. Identifying the poor first requires the definition of a poverty cutoff for each component. The index is then computed as an arithmetical mean of dimensions. Second, a cross-dimensional cutoff is defined: an individual is considered poor when their index is higher than a poverty line.

Data-driven indexes provide a less consistent field. One might differentiate datadriven indexes based on cardinal information from data-driven indexes derived from ordinal information. The former are primarily built using data analysis processes, which can be distinguished into two sets: descriptive and explanatory models (Krishnakumar and Nagar, 2008). Indexes of Social Development (InSocDev) are built by combining these two approaches, as described by Dickes et al. (2010) and then Acket et al. (2011). Their aim is to provide a multidimensional index of social cohesion. Data are selected on Bernard (1999) and Chan et al.'s (2006) theoretical grounding. Multidimensional Scaling (MDS), as a descriptive analysis, is first used to select dimensions of the index. Then, an explanatory analysis is driven using a Confirmatory Factor Analysis (CFA), which confirms the hierarchical structure provided by MDS. The final index is computed with an arithmetical aggregation. Data-driven indexes based on ordinal information are convincingly applied by Foa and Tanner (2011), who build a composite index from a number of social indicators, and deal with the drawbacks of missing data using matching percentile methodology. Each component is standardized, and computed using the fiveyear values around the anchor year. The authors focus on the rank-hence, on ordinal information - in order to compute the index. A match list is generated, and the input list is composed by the sub-index values computed. Then, the score of a country is computed by comparing the input to the match list according to its rank. The index score is obtained using a recursive process until convergence is achieved for the countries scores.

As the first aim of our index is comparative, at both micro- and macro-levels, we chose to implement it normatively. Poverty is considered as having multidimensional bases, some of which are ordinal. We describe here an index $P_{i}$ measuring $K$ dimensions of poverty across a population of $N$ individuals. Let $1-x_{i, k}$ indicate the deprivation of individual $i$ in dimension $k$.

\subsection{Choice of dimensions}

We distinguish three dimensions of these relational capabilities, considering the different spheres of life (economic, personal and civic/political (Walzer, 1983)):

- to be integrated into networks;

- to have specific attachments to others, including friendship and love;

- to commit to a project within a group, which aims at serving a common good or a social interest; to take part in decision-making in a political society. 


\section{Integration into networks}

Integration into networks is the first component of relational capability. From the first network in which a newborn is integrated - i.e. their family - to the community that gathers around the deceased person, human life is spent in networks. At this stage, we consider imposed and inherited networks, as well as chosen networks. Part of our identity forms through given networks, and part of it through our voluntary commitment to others (Coleman, 1988; Jackson and Wolinsky, 1996). Lack of freedom, which is the very definition of prison, is a means of preventing people from belonging to networks that constitute social life. Similarly, exclusion consists of the absence or the weakness of participation in networks due to isolation and the inability to escape it Boltanski and Chiapello, 1999). The lack of relational capability can be measured through a weak participation in networks, whether institutional or not.

The indicators we use to calculate our index are: the number of people in the household, employment status (i.e. whether the person has a stable job with professional relations), access to transport, and access to information/relational assets (mobile phone, radio, TV).

Two aspects of this first pillar of the RCI deserve specific comments:

- Employment: OECD's report on social cohesion (Society at glance: OECD 2005; 2011) considers employment and unemployment as factors of "self-sufficiency," that is "active participation in the economy and society, and autonomy in activities of daily living." Indeed, employment highlights people's capacity of to be financially independent, but is also a major factor of formal integration into professional networks and an opportunity of daily socialization (Paugham and Russell, 2000).

From the same perspective, the UNDP's Human Poverty Index for high-income OECD countries (1997) and the Leaken indicators on poverty and social exclusion, defined by the European Council (HPI-2 2001), consider long-term unemployment as a major indicator of social exclusion.

- Relational assets: A number of indicators consider ownership of a telephone, TV, car or computer as indicators of the households' level of equipment (Social Development Index: Ray (2008); Multidimensional Poverty Index: Alkire and Santos (2010)). Rather than private ownership, RCI focuses on access to transportation and communication goods. Indeed, such resources allow the enlargement of networks, access to new opportunities (commuting, short- or long-distance migration) and, more broadly speaking, entering into the dynamics of modernity and globalization. Being aware of the political, social or cultural news is also a factor of social integration, and a capacity to develop shared references with others.

\section{Private relations}

The second dimension of relational capability concerns feelings for others - namely friendship and love - in an interpersonal relationship. Human growth is favored by the quality of love a human being receives and gives (Nussbaum, 2000). This love may be 
more or less exclusive; it implies the relation between two free persons in the above-defined sense. Love is the highest expression of human freedom as autonomy and interdependence. We measure this aspect using different features: by whom a person feels he/she is loved, the number of close friends, and the number and the nature of the persons to whom the individual can turn in case of difficulties (financial, professional, etc.).

The quality of interpersonal relationships, the level of trust within an organization and respect for the private life of its members are also of interest when assessing this dimension of relational capability. This is related to the importance given to human capital and to the human quality of the leaders within a given institution (George, 2003).

\section{Civic commitments (participation)}

The third dimension consists in the civic commitments of an individual; i.e., her voluntary commitment to others for a specific project concerning a common good or a collective interest. It implies participation in the decision-making process within a political community. We focus here on chosen networks and, more specifically, on personal commitment in society. This commitment can take different forms: political, social, cultural, and associative (Alkire, 2002, Nussbaum, 2003). The importance of any such commitment is closely related to the definition of a fair society as one that promotes a complex equality (Walzer, 1983) among citizens: complex equality implies the assessment of the capability shared by anybody in a given community to be recognized in one or another sphere of their life; this recognition is facilitated via active and autonomous involvement in a social network.

This commitment to different networks in a pluralist society can be captured by several indexes: political vote, participation of everyone - including the worse off - in the decision-making process at a local level, voluntary commitment to a group or association within the community, etc.

This third dimension of relational capability is ultimately focused on considering every other person as an end: such an attitude requires the special care one might have for an individual - through friendship and love - to be extended to any interpersonal relation, either directly or via mediation by institutions. This is what Paul Ricœur calls the logic of overabundance, concerning the implementation of the biblical Golden Rule in social networks (Ricœur, 1990). The negative definition of the Golden Rule ("do not do to others what you would not want them to do to you") is close to a minimal and negative ethical principle ("do no harm"), and expresses a logic of equivalence. But the Golden Rule in its positive side ("do unto others as you would have them do unto you") has a broader meaning: it is an invitation to actively contribute to the good of others, without any reciprocity. It opens the door to an excess: give according to your capacity, without expecting an equivalent gift in return. This attitude clearly involves face-to-face encounters (cf. second component: private relations) but it may also be incorporated into social, economic and political institutions: it enables respect for the uniqueness of every person, and expresses the objective of a social organization serving the dignity of each of its members. 
We can measure this dimension by referring to the level of gifts given or received, the time and energy freely given to community projects, and the level of trust towards unknown others.

\begin{tabular}{|c|c|c|}
\hline Dimension & Components & Deprived if \\
\hline Integration to network & $\begin{array}{l}\text { Employment status } \\
\text { Access to transport } \\
\text { Access to telecommunications } \\
\text { Access to information }\end{array}$ & $\begin{array}{l}\text { No stable job with regular professional relations } \\
\text { No means of transport } \\
\text { Uses a phone, a computer or the Internet } \\
\text { less than once a week } \\
\text { Gets news from radio, television or newspaper } \\
\text { less than once a week }\end{array}$ \\
\hline Private relations & $\begin{array}{l}\text { Number of people in the household } \\
\text { Family ties } \\
\text { Close friends, emotional support } \\
\text { Financial support } \\
\text { Trust in the community }\end{array}$ & $\begin{array}{l}\text { Lives alone } \\
\text { No trust in relatives } \\
\text { No close friends providing psychological and } \\
\text { emotional support } \\
\text { No financial support from relatives or acquaintances } \\
\text { No trust in people the individual knows }\end{array}$ \\
\hline Civic commitment & $\begin{array}{l}\text { Membership } \\
\text { Collective action } \\
\text { Vote } \\
\text { Solidarity } \\
\text { Trust in others }\end{array}$ & $\begin{array}{l}\text { No active membership in a group } \\
\text { (religious, trade-unions and/or business association) } \\
\text { No participation in political actions } \\
\text { (meetings, petitions, boycotts, demonstrations) } \\
\text { Does not vote } \\
\text { No active membership in a common-interest group } \\
\text { No trust in unknown people }\end{array}$ \\
\hline
\end{tabular}

Table 2: Relational Capability Index: Dimensions and components

\subsection{Cutoffs and weights}

\subsubsection{Cutoffs for each component and for dimensions}

We define three sets of poverty lines, and implement different cutoffs to test the robustness of our results with respect to threshold variations.

- First, we define poverty lines at the component level. Our choices of dimensions and deprivation cutoffs (or poverty lines) are defined in Table 2.

- Second, we define a poverty line within each dimension. Someone who is deprived in at least one component of Dimension 1 (respectively 2 and 3) is poor in this dimension.

- Third, we define a deprivation cutoff for the index.

In the empirical applications presented in this paper, we use binary values for components: let $c_{i, j}$ denote component $j$ in dimension $k$ for individual $i, i=1, \ldots, N$, $j=1, \ldots, C_{k}$, where $C_{k}$ is the total number of components in dimension $k$, we set $c_{i, j}=0$ if $i$ is deprived in component $j$ and $c_{i, j}=1$ otherwise. We choose the most restrictive dimensional poverty lines: people are deprived in a dimension if and only if they are deprived in at least one component of this dimension, i.e. $x_{i, k}=1 \Longleftrightarrow \forall j \in\left\{1, \ldots, C_{k}\right\}, c_{i, j}=1$ 
We then define the poverty line of the index as the existence of a deprivation in at least one dimension: $\exists k \in\{1, \ldots, K\}, x_{i, k}<1$. This choice is in line with our Walzerian perspective, since each of our dimensions represents a specific sphere of life and we consider that someone who reaches the greatest score in terms of capabilities in at least one sphere should not be considered as deprived, whatever their score in the other spheres. Nonetheless, we aim to test other sets of cutoffs in future work, at both the dimension and index levels.

\subsubsection{Choosing weights}

Weights represent the importance given to:

- one set of capabilities compared to others (weights between dimensions);

- one component compared to another within dimensions;

- part of the population (e.g. the most deprived) compared to another (weights distributed among people).

First, for each step of the computation, we choose normative weights, defending an agnostic point of view (see section 4 below). All the components within dimensions are equally weighted in an index computation. Hence, for $x_{i, k}$ a dimension of poverty for individual $i, k=1, \ldots K, x_{i, k}$ is computed from components $c_{i, j}, j=1, \ldots, C_{k}$, as follows :

$$
x_{i, k}=\frac{1}{C_{k}} \times \sum_{j=1}^{C_{k}} c_{i, j}
$$

Then, following Walzer (1983), the individual index is computed with maximin groundings. $\left(1-x_{i, k}\right)$ measures the deprivation in dimension $k$ for individual $i$. A geometrical mean of $\left(1-x_{i, k}\right)$ makes it possible to stress the complementarity relationship between deprivations: increasing the score of one dimension is sufficient for global improvement.

The different versions of the RCI we present in section 5 are based on geometrical means of $\left(1-x_{i, k}\right)$ on $i$ and $k$. They are specific elements of the family of indexes that we present in section 4 , associated with three different families of weights. Future work should include more advanced empirical applications of the axiomatic viewpoint, with the intension of testing other families of weights.

\subsection{Comparisons with existing indicators}

\subsubsection{Socio-economic indicators}

Many development indexes and sets of indicators aim to measure living standards (income; material deprivation (see Bossert et al. (2009)); access to infrastructures), as well as access to education, health and social services as factors of social development. These multidimensional measures of material inequalities and exclusion have been developed in 
response to criticisms of the measurement of living standards based on monetary incomes. They appear to be particularly relevant in developing countries, where monetary incomes are often marginal.

Because they focus on material deprivation and access to public services, these dimensions reflect direct responsibilities of governments, and can be directly improved by appropriate public policies. By identifying the level of deprivation of the poorest (Rawls, 1971), they definitively stress major issues of social cohesion and social development.

From our perspective, these indicators are complementary with the RCI view: programs or policies should simultaneously foster the improvement of living standards and the development of social relationships in communities, and in the whole of society. The most universal of these indicators is the Multidimensional Poverty Index Alkire and Santos, 2010; UNDP, 2010). Table 3 presents the dimensions and cutoffs on which this is based.

\begin{tabular}{|c|c|c|c|}
\hline Dimension & Indicator & Weight & Deprived if \\
\hline Education & $\begin{array}{l}\text { Years of } \\
\text { school attendance }\end{array}$ & $\begin{array}{l}1 / 6 \\
1 / 6\end{array}$ & $\begin{array}{l}\text { No household member has completed } 5 \text { years of schooling } \\
\text { Any school-aged child is not attending school in years } 1 \text { to } 8\end{array}$ \\
\hline Health & $\begin{array}{l}\text { Child mortality } \\
\text { Nutrition }\end{array}$ & $\begin{array}{l}1 / 6 \\
1 / 6\end{array}$ & $\begin{array}{l}\text { Any child has died in the family } \\
\text { Any adult or child for whom there is nutritional } \\
\text { information is mal nourished }\end{array}$ \\
\hline $\begin{array}{l}\text { Living } \\
\text { standards }\end{array}$ & $\begin{array}{l}\text { Electricity } \\
\text { Drinking water } \\
\text { Sanitation } \\
\text { Flooring } \\
\text { Cooking fuel } \\
\text { Asset ownership }\end{array}$ & $\begin{array}{l}1 / 18 \\
1 / 18 \\
1 / 18 \\
1 / 18 \\
1 / 18 \\
1 / 18\end{array}$ & $\begin{array}{l}\text { The household has no electricity } \\
\text { The household's sanitation facility is not improved (according to } \\
\text { MDG guidelines) or is improved but is shared with other households } \\
\text { The household does not have access to clean drinking water (MDG) } \\
\text { or clean water is more than } 30^{\prime} \text { walking from home } \\
\text { The household has dirt, sand or dung floor } \\
\text { The household cooks with dung, wood or charcoal } \\
\text { The household does not own more than one of the following: radio, TV, } \\
\text { telephone, bike, motorbike or refrigerator, and does not own } \\
\text { a car or truck }\end{array}$ \\
\hline
\end{tabular}

Table 3: The Multidimensional Poverty Index

\subsubsection{Indicators of social cohesion and exclusion}

Various international institutions have integrated the social cohesion into their strategy, and also their monitoring device. They have built a range of statistical indicators to reiterate the complexity of social cohesion.

The Social Cohesion Indicator (Leaken Indicators, \{Eurostat\} (2003)) initiated the institutional research on social cohesion indicators (Atkinson et al., 2002; Marlier, 2007). We focus here on the four composite indexes that are closest to our perspective, in order to stress the specificity of the RCI. Table 4 provides a synthetic outlook on the dimensions and components used by each one.

- The indicator of social exclusion (Chakravarty and D'Ambrosio, 2006) combines socio-economic dimensions and private relations, whereas our index does not entail information on economic poverty or basic needs. 
- The Social Health Indicator (Jany-Catrice, 2009) tries to capture both poverty and inequality and the level of people's social integration. Our index does not provide data on economic inequality.

- The Multidimensional Social Exclusion Index (UNDP Europe \& CIS, 2011) aims to capture all kinds of exclusion: economic, social services, and exclusion from participation in civil and social life and networks. Our RCI focuses on this last form of exclusion. It entails a number of variables that are related to material conditions, but these are not considered to impede the quality of relations among people; nor are they considered in terms of basic needs (either economic or social).

- The Better Life Index (OECD 2012) entails two chapters that are close to our RCI: social networks and civic commitment and governance. The three dimensions related to "social networks" are personal relations (close to our second component: private relations), relations with collectivity (close to our second component: civic commitment), and norms and values (captured through the level of trust, which is close to our third dimension). The "civic commitment and governance" chapter entails three dimensions: the first, "civic commitment," is close to our own, including voting and political participation (for us: collective action and membership). The second and third dimensions, "quality of governance" and "trust in political institutions," are not captured by our index. We focus on more immediate relationships between citizens and society.

To summarize, our index is the only one to focus on personal, social and political bonds, without providing data on economic exclusion. As mentioned above, it enables the levels of social ties and relational deprivations to be compared in different contexts, independently of the economic wealth issues that are captured by other indexes such as the MPI. We aim to study such comparisons in forthcoming work. 


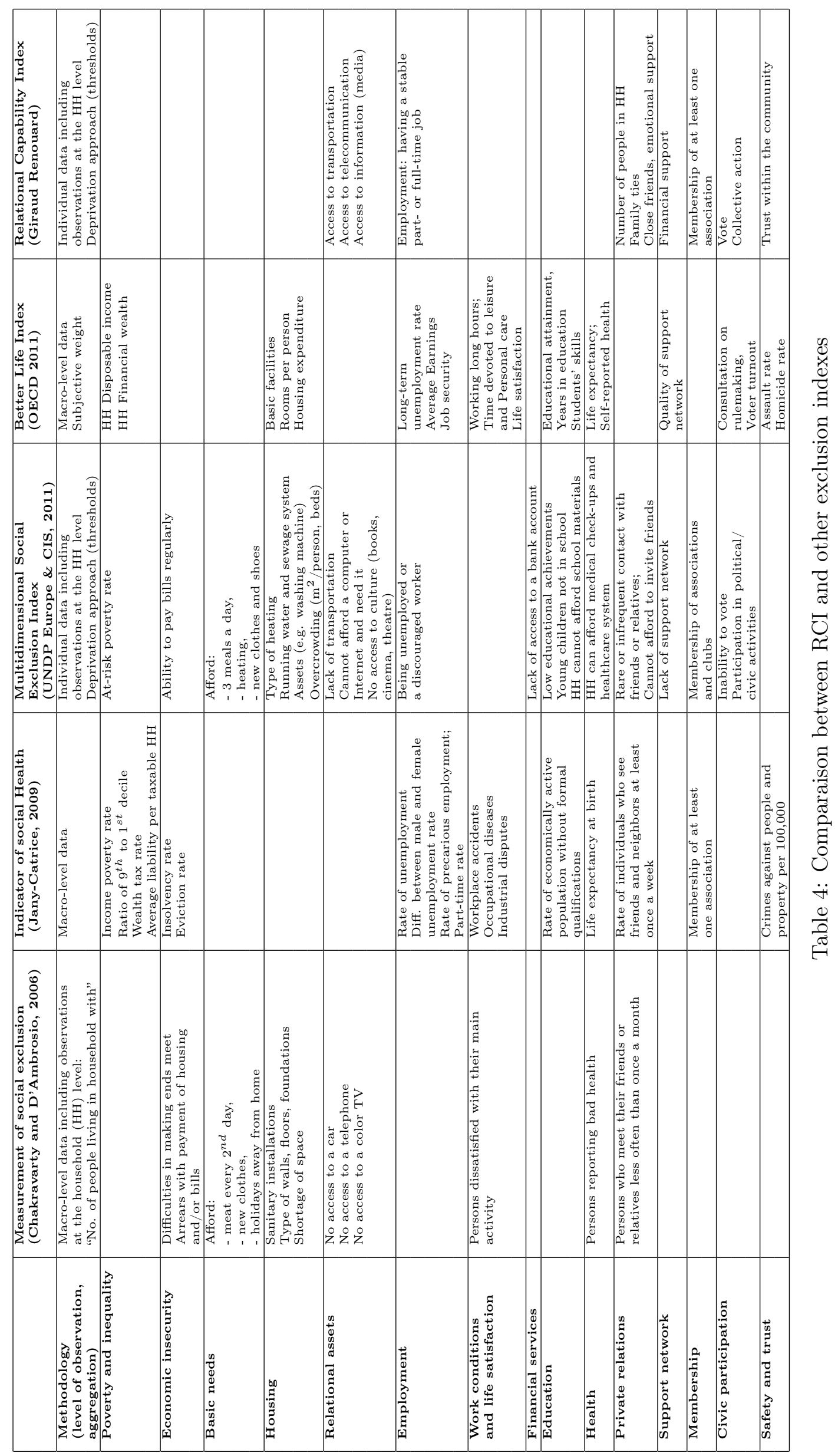




\section{The axiomatic: building coherent poverty indexes}

\subsection{Building the Relational Poverty Index}

As acknowledged by Villar (2010), "Defining a poverty measure in a truly multidimensional context involves a number of subtle and difficult issues: choosing the appropriate poverty dimensions beyond income or wealth, deciding on whether they all are equally important, fixing sensible thresholds in those dimensions and setting criteria to identify as poor those individuals whose achievements lie partially below them, defining an overall measure of poverty intensity, etc. Those difficulties anticipate that many compromises are required and, indirectly, that the axiomatic approach may be the best way to deal with this type of problem as it makes explicit all those compromises." 5 Here, we provide an axiomatization for a family of Multidimensional Poverty Indexes. In the next section, we will present how to use specific elements of this family with real-world data.

Each index can be characterized as lying somewhere between the two extreme points of our family of indexes: the geometric mean (Villar, 2010) and the Rawlsian Maximin (Rawls, 1971). Although both social choice correspondences have been thoroughly studied from the social choice theoretical viewpoint ${ }^{6}$ we are not aware of any attempt to link these two major concepts of justice with the concerns involved in the literature devoted to poverty measurement. This paper is a first attempt to fill this gap.

We suggest that the geometric mean can be interpreted as a (hyperbolic) version of the "utilitarian" viewpoint. With this interpretation in mind, our family of indexes builds a bridge between celebrated theories of justice and poverty measurements. An alternative standpoint enables us to characterize each one of our indexes as being the supremum of the weighted geometric averages, with the sup being taken over some collection of weights of dimensions and people. When the collection of weights reduces to the uniform vector, we are back to the standard geometric mean (this is the "utilitarian" solution). When the underlying collection of weights includes the whole unit simplex over dimensions and people, then we get the Maximin solution. One possible interpretation is as follows: suppose that the economist who is in charge of measuring poverty in a given population reflects as if she were in Rawls's original position. Beyond the veil of ignorance, the point that is ignored is related to which role one will endorse (as in the standard, political interpretation of Rawls's theory of justice), but in which dimension one will get some talent (or some endowment, or some "social capital"). Thus, uncertainty bears on dimensions, rather than on persons. In addition, from the viewpoint of the economist standing beyond the veil, there might be some ambiguity concerning the probability according to which talents and deprivations will be distributed. As a result, if the economist has no prejudice about the distribution of talents and deprivations, they might opt for the Maximin solution as a way to measure multidimensional poverty. If, on the other hand, the economist has good reasons to believe that the distribution will

\footnotetext{
${ }^{5}$ See Dardadoni (1995), Ravallion (1996), Tsui (1996), Bourguignon and Chakravarty (2003), Lugo and Maasoumi (2008), Alkire and Foster (2008), Wagle (2008), and Chakravarty (2009).

${ }^{\circ}$ See Dhillon and J.-F. Mertens (1999) and Fleurbaey and Maniquet (2008) to name but a few pathbreaking papers in this area.
} 
be uniform, they may choose the "utilitarian" solution (i.e., in our context, the geometric average). Otherwise, she might choose an index in our family which lies somewhere between the first two. If desired, it is also possible to include ambiguity about the persons (and not only dimensions) in the non-symmetric version of our family of indexes.

To the best of our knowledge, this is the fist attempt to formally fill the gap between theories of justice and poverty measurements. As we take inspiration from Artzner et al. (1999) (where an additive version of a similar axiomatization was introduced in order to measure the risk position of a portfolio), we call coherent a multidimensional poverty index belonging to our family. We finally show that such indexes satisfy the following properties, which are considered as desirable by the literature 7

(i) Each index is continuous: slight changes in the achievements of certain persons only induce slight changes in the poverty measurement;

(ii) Each index is ordinal, in the sense that it does not depend upon the choice of the specific units in which dimensions of achievements are measured. This property deserves some comment. In Alkire and Foster (2008), it is argued that data describing capabilities and functionings, in the spirit of Sen's Multidimensional Human Index, are ordinal in nature. They therefore may lack a basis for comparisons across dimensions. This, of course, is a challenge for Multidimensional Poverty measurement. In the abovequoted paper, indeed, only one kind of measure is shown to be ordinal in that sense (the $M^{0}$ measure in their parlance) while the others are not. At the same time, this ordinal measure fails to satisfy a number of other properties. In particular, it cannot capture the intensity of poverty - a failure that can be viewed as arising from its being a piecewise constant (and hence discontinuous) measure. Here, we prove that coherent poverty measures are ordinal in the following sense: If one multiplies any dimension by $\lambda>0$ (both for achievements and for the poverty cut-off), then the "poor" set is unaffected, while the index, $P$, is simply multiplied by $\lambda$. As a consequence, a normalized version of the index, $P /\|P\|$, is independent of such changes in the dimension unit used. Since, on the other hand, $P$ is continuous, this is the first example (to the best of our knowledge) of a continuous and ordinal Multidimensional Poverty measure.

(iii) It yields a criterion for "relative poverty" that depends upon the whole population under scrutiny;

(iv) The marginal rate of substitution among subjects or among dimensions is decreasing. The reduction in the deprivation 8 of dimension $k$ for poor individual $i$ required to compensate an increase in the deprivation of dimension $k$ for individual $h$ is larger, the higher the initial level of deprivation in $i$.

(v) As in Villar (2010), it is multiplicatively decomposable by population subgroups (but it does not satisfy Subgroup Decomposability in the additive form given in Bourguignon and Chakravarty (2003)). This property says the following: if the population is partitioned into subgroups, the overall poverty index corresponds to the

\footnotetext{
${ }^{7}$ See, e.g., Bourguignon and Chakravarty $(2003)$ and Alkire and Foster $(2008)$.

${ }^{8}$ Recall that a person is said to be deprived in one dimension whenever their achievement falls below the cut-off or dimension-specific poverty line.
} 
weighted average of subgroup poverty values, where the weights correspond to population shares.

(vi) In certain circumstances, we may have additional information that allows us to regard certain dimensions and/or certain subgroups of the population as meriting a greater relative weight than others. Each index can be adjusted so as to capture this kind of requirement. Of course, if desired, it can as well be made symmetrical among persons.

(vii) It verifies the transfer principle (Villar, 2010): a reduction of size $\delta>0$ in the deprivation with respect to dimension $k$ of a poor person $i$ who is worse off in this dimension than another poor person, $j$, more than compensates for an increase of the same size, $\delta$, in the deprivation of $j$, provided their relative positions remain unaltered.

(viii) Principle of population: a replica of the population does not change the poverty measure.

The subsequent section is organized as follows. The next subsection provides the model and makes the link between the "utilitarian" standpoint and the geometric mean explicit. Subsection 5.3 deals with the axiomatization of coherent multidimensional poverty indexes. The last subsection provides the main properties of this family of indexes.

\subsection{The model}

Let $\mathbf{N}=\{1, \ldots, N\}$ denote a society consisting of $N$ individuals and let $\mathbf{K}=\{1, \ldots, K\}$ be a set of dimensions.

A social state is a matrix, $y=\left(y_{i j}\right)_{i j} \in \mathcal{M}_{N \times K}\left(\mathbb{R}_{++}\right)$, with $N$ rows, one for each individual, and $K$ columns, one for each dimension. The entry $y_{i j} \in \mathbb{R}_{++}$describes the value of variable $j$ for individual $i$. Since we are going to deal with ordinal poverty measures, there is little loss of generality in imposing, from the outset, that all variables be strictly positive $9^{9}$ A vector $\mathbf{z} \in \mathbb{R}_{++}^{K}$ of reference values describes the poverty thresholds for all dimensions. How these thresholds are fixed is definitely an important issue, but we leave it aside here and take $\mathbf{z} \in \mathbb{R}_{++}^{K N}$ as a given. Those reference values may have been fixed externally (absolute poverty lines), or may depend on the data of the social state matrix itself (relative poverty lines, such as a fraction of the median or the mean value). The units in which achievements are measured are chosen so that $\mathbf{z}>\mathbf{1}:=$ $(1, \ldots, 1) \in \mathbb{R}_{++}^{K N}$ When all individuals are attributed the same cut-offs, $\mathbf{z}=(z, \ldots, z)$, for some reference vector $z \in \mathbb{R}_{++}^{K}$. In this case, if $x_{i} \leq z$, then individual $i$ can be said to be poor (with the converse being false).

We denote by $N_{p}(y ; \mathbf{z}) \subset \mathbf{N}$ the set of poor that results from a social state matrix $y$ and a vector, $z$, of reference values. The number of poor people is $n_{p}(y ; \mathbf{z}):=\left|N_{p}(y ; \mathbf{z})\right|$.

\footnotetext{
${ }^{9}$ We cannot claim that this entails no loss of generality at all. Indeed, if some achievement is "naturally" given as being (strictly) positive, then, whether it is scored $\varepsilon>0$ or $\lambda \varepsilon>0$ does not matter. However, if the original achievement was 0 , then, replacing it by $\varepsilon>0$ might have an effect on the poverty measure. The same problem arises in, for instance, $\operatorname{Seth}(2009)$.

${ }^{10}$ Given two vectors $x, y, x<<y$ if the strict inequality holds coordinatewise.
} 
As we shall see, $N_{p}(y ; \mathbf{z})$ (hence $\left.n_{p}(y ; \mathbf{z})\right)$ will be determined endogenously by our multidimensional poverty index).

\subsubsection{The utilitarian index}

A poverty index is a map of $P: \mathbb{R}_{++}^{K N} \rightarrow \mathbb{R}_{+}$. We begin with three axioms that unambiguously characterize the "utilitarian" poverty index.

The first one, anonymity, says that all agents and all dimensions are equally important:

Anonymity. Let $x \in \mathbb{R}_{++}^{K N}$, and let $\pi \in \mathcal{S}_{K N}$ denote a permutation over its components $\{1, \ldots, K N\}$. Then, $P(s)=P(\pi(s))$.

The second Axiom implies that $P$ reduces to the identity mapping on the diagonal of $\mathbb{R}_{+}^{K N}$ :

Normalization. Let $s \in \mathbb{R}_{++}^{K N}$ be such that $s_{i j}=a \forall i, j$. Then $P(s)=a$.

The last property requires that the difference between the new and the initial values of $P$, when subject $i$ 's achievement relative to dimension $j$ changes from $s_{i j}$ to $t_{i j}$, be a monotone function of the difference between $s_{i j}$ and $t_{i j}$.

Difference Monotonicity. Let $s, t \in \mathbb{R}_{+}^{K N}$ be such that $s_{h q}=t_{h q} \forall(h, q) \neq(i, j)$. Then

$$
P(s)-P(t)=g_{i j}\left(s_{i j}-t_{i j}\right),
$$

for some increasing function $g_{i j}: \mathbb{R}_{+} \rightarrow \mathbb{R}$. Since $g_{i j}(0)=0$, it follows that $g_{i j}(x) \geq 0$ if, and only if, $x \geq 0$.

Proposition 1. An index $P(\cdot)$ satisfies anonymity, normalization and difference monotonicity if, and only if, it takes the form

$$
P(s)=\frac{1}{K N} \sum_{i \in N, j \in K} s_{i j} .
$$

This index corresponds to the familiar arithmetic average, and we denote it $P_{U}$.

Proof. Let $s \in \mathbb{R}_{+}^{K N}$. By difference monotonicity and normalization,

$$
\begin{aligned}
P\left(s_{11}, 0, \ldots, 0\right)-P(0, \ldots, 0) & =g_{11}\left(s_{11}\right) \\
P\left(s_{11}, s_{12}, \ldots, 0\right)-P\left(s_{11}, 0, \ldots, 0\right) & =g_{12}\left(s_{12}\right)
\end{aligned}
$$

so that 


$$
P(s)=P(0)+\sum_{i, j} g_{i j}\left(s_{i j}\right) .
$$

By anonymity, $g_{i j}(\cdot)=g(\cdot) \forall i, j$. The normalization axiom yields: $P(0, \ldots, 0)=0$. Moreover,

$$
P(a, \ldots, a)=K N g(a)=a .
$$

Therefore, $g(a)=\frac{a}{K N}$. The conclusion follows.

\subsubsection{The geometric average}

The link between the (admittedly fairly classical) index, $P_{U}$, and the geometric average is given by the following transformation:

Consider the following poverty index, $G(\cdot)$, defined by $\mathbb{R}_{++}^{K N}$ :

$$
G(x):=\left[\prod_{k, h} x_{k, h}\right]^{\frac{1}{k n}} .
$$

Given a vector, $x \in \mathbb{R}_{++}^{K N}$, let us denote by $\ln x$ the vector whose coordinates are $\ln x_{k, h}$, every $h, k$. Obviously,

$$
G(x)=\exp U(\ln x) .
$$

From this very simple computation, one can deduce the axiomatization provided by Villar (2010) that fully characterizes the geometric average as a poverty index. Indeed, it follows from (2) that $G$ must verify the anonymity and normalization axioms together with the following ratio monotonicity:

Ratio Monotonicity Let $s, t \in \mathbb{R}_{++}^{K N}$ be such that $s_{h q}=t_{h q} \forall(h, q) \neq(i, j)$. Then,

$$
\frac{G(s)}{G(t)}=g_{i j}\left(\frac{s_{i j}}{t_{i j}}\right)
$$

for some increasing function $g_{i j}: \mathbb{R}_{++} \rightarrow \mathbb{R}$. Since $g_{i j}(1)=1$, it follows that $g_{i j}(x) \geq 1$ if, and only if, $x \geq 1$.

In other words, the geometric (or Cobb-Douglas) average may be viewed as the outcome of the utilitarian rule after the transformation given by (2). In the following section, we show that $G(\cdot)$ is but one extremal point of a whole family of Poverty indexes that can be constructed in quite a similar way. The other extremal index of this family turns out to be the Maximin rule. 


\subsection{Coherent poverty indexes}

In order to define a coherent poverty index, we impose some axioms on the mapping $P(\cdot)$. For this purpose, we define a poverty exit set, $\mathcal{E} \subset \mathbb{R}_{++}^{K N}$. A population belongs to $\mathcal{E}$ whenever it is not poor.

\subsubsection{Axioms for $\mathcal{E}$}

In order to build an ordinal index (i.e. an index that does not depend upon the choice of unities in which dimensions are measured), we consider only normalized achievements. That is, if $x \in \mathbb{R}_{++}^{K N}$ is a given achievement, we shall deal with $\mathbf{x}:=\left(x_{h k} / \mathbf{z}_{h k}\right)_{h, k}$.

Axiom 1. $1+\mathbb{R}_{+}^{K N} \subset \mathcal{E}$.

Consider, now, a population such that all its individuals have achievements (before normalization) that are all strictly below the thresholds given by z. Obviously, such a population should be considered poor. This is the content of the next axiom. ${ }^{11}$

Axiom 2. $\mathcal{E} \cap\left(1+\mathbb{R}_{-}^{K N}\right)=\{1\}$.

For every $x, y \in \mathbb{R}_{++}^{K N}$, let $x \square y$ denote the vector in $\mathbb{R}_{++}^{K N}$ whose coordinates are $x_{k, h} z_{k, h}$. Consequently, $1 / y$ denotes the (unique) vector such that $y \square 1 / y=\mathbf{1}$, while $x^{\lambda}$ is the vector with coordinates $x_{k, h}^{\lambda}$. The "box" product, $\square \cdot$, is to be interpreted as formalizing a change in the achievements of the population under scrutiny. For instance, $x \square \mathbf{1}=x$ stands for "no change". In contrast, $x \square 0=0$ represents a radical depletion of the population, etc. For an arbitrary vector, $y \in \mathbb{R}_{++}^{K N}, x \square y$ will represent a change that may be dimension- and individual-dependent.

A set $\mathcal{F} \subset \mathbb{R}_{++}^{K N}$ is multiplicatively convex whenever, as soon as $x, y \in \mathcal{F}$, it results in $x^{\alpha} \square y^{1-\alpha} \in \mathcal{F} \forall \alpha \in[0,1]$.

Axiom 3. The poverty exit set, $\mathcal{E}$, is multiplicatively convex.

Axiom 1 says that, if all the individuals of a population exhibit all their achievements above the threshold (i.e., if $\mathbf{x} \geq \mathbf{1}$ ), this population is not poor. Conversely, if $\mathbf{x}<<1$, Axiom 2 implies that the population is poor. Ambiguity remains only whenever some individuals exhibit some achievements above the threshold, and others do not. Our last axiom deals with such ambiguous cases. Suppose that a population, $x$, is not poor. Take $\lambda>0$ and consider the auxiliary population given by $x^{\lambda}$. Axiom 4 says that this new population should not be considered as poor either. Clearly, if $x \square 1 / \mathbf{z} \geq \mathbf{1}$ (respectively $x \square 1 / \mathbf{z}<\mathbf{1}$ ), then $\left(x^{\lambda} \square 1 / \mathbf{z}\right) \geq \mathbf{1}$ (respectively $<\mathbf{1}$ ), so that the auxiliary population turns out, indeed, not to be poor (respectively to be poor). What the next axiom says

\footnotetext{
${ }^{11}$ Actually, Axiom 2 says a little bit more, since it implies that, in the case of a single-person population, this person will be poor if none of their achievements end up strictly above the cut-off, and at least one of their achievements stay strictly below this cut-off. We could replace Axiom 2 with the weaker $\mathcal{E} \cap\left(\mathbf{1}+\mathbb{R}_{--}^{K N}\right)=\emptyset$. But our other axioms would nevertheless strengthen it into Axiom 2 in most cases of interest for practical purposes.
} 
is that this property should not hold only for the extreme cases envisaged by Axioms 1 and 2, but also for the "ambiguous" cases.

A set $\mathcal{F} \subset \mathbb{R}_{++}^{K N}$ is a multiplicative cone whenever, as soon as $x \in \mathcal{F}$, it results in $x^{\lambda} \in \mathcal{F}$ for any $\lambda \geq 0$.

Axiom 4. The poverty exit set, $\mathcal{E}$, is a multiplicative cone.

Examples The two following sets verify all four axioms.

a) The "utilitarian case." Consider

$$
\mathcal{E}:=\left\{\mathbf{x} \in \mathbb{R}_{++}^{K N} \mid G(\mathbf{x}) \geq G(\mathbf{1})\right\} .
$$

$\mathcal{E}$ is the upper-set of the hyperbola $\{\mathbf{x}: G(\mathbf{x})=\lambda\}$, and is closed and (additively) convex.

b) The "Rawlsian case." Consider

$$
\mathcal{E}:=\{\mathrm{x} \geq \mathbf{1}\}
$$

$\mathcal{E}$ is an affine closed, convex (additive) cone.

Although it is not necessary for the core of our theory, the next axiom will prove useful.

Axiom 5. $\mathcal{E}$ verifies the following Anonymity property: Let $x=\left(x_{1}, . ., x_{n}\right) \in \mathbb{R}_{++}^{K N}$ and $\sigma(x)=\left(x_{\sigma(1)}, \ldots, x_{\sigma(N)}\right) \in \mathbb{R}_{++}^{K N}$ the vector obtained after having swapped its individuals with the permutation $\sigma \in \mathcal{S}_{N}$. Then,

$$
\mathbf{x} \in \mathcal{E} \Longleftrightarrow \sigma(\mathbf{x}) \in \mathcal{E} \forall \sigma \in \mathcal{S}_{N}
$$

\subsubsection{Axioms for $P$}

Given a set $\mathcal{E}$, the poverty index, $P_{\mathcal{E}}$, is defined as a measure of the minimal additional "achievements" that have to be added to a given distribution so that the population can be considered as non-poor; i.e., so that the resulting distribution belongs to $\mathcal{E}$. Obviously, $P_{\mathcal{E}}$ will heavily depend upon the choice of $\mathcal{E}$. This is why the axiom studied here only defines a family of poverty indexes, with each index being identified through its corresponding poverty exit set.

Given $\mathcal{E}$, the mapping $P_{\mathcal{E}}(\cdot)$ is defined as:

$$
P_{\mathcal{E}}(\mathbf{x}):=\inf \left\{\tau \in \mathbb{R} \mid \mathbf{x} \square \mathbf{z}^{\tau} \in \mathcal{E}\right\} .
$$

Axiom 1 implies $P_{\mathcal{E}}(\mathbf{1})=0$, and $\lim _{\mathbf{x} \rightarrow 0} P(\mathbf{x})=+\infty$. Conversely, given a poverty exit index, $P(\cdot)$, one can define the poverty exit set, $\mathcal{E}_{P}$, as

$$
\mathcal{E}_{P}:=\left\{\mathbf{x} \in \mathbb{R}_{++}^{K N} \mid P(\mathbf{x}) \leq 0\right\} .
$$


We now state several properties for $P$. As we shall see, these can be deduced from Axioms 1-4 on $\mathcal{E}$ via (3). Conversely, Axioms 1-4 can be deduced from the following properties of $P$, via $(4)$.

Axiom Hi (Homothetic invariance) $\forall \mathbf{x} \in \mathbb{R}_{++}^{K N}, \alpha \in \mathbb{R}, P\left(\mathbf{x} \square \mathbf{z}^{\alpha}\right)=P(\mathbf{x})-\alpha$.

An easy consequence of Axiom $\mathrm{HI}$ is that $P\left(\mathbf{x} \square \mathbf{z}^{P(\mathbf{x})}\right)=0$ - which is consistent with the interpretation of $P(\cdot)$ given by (3). It follows that

$$
\forall \mathbf{x}, \mathbf{x} \square \mathbf{z}^{P(\mathbf{x})} \in \mathcal{E} .
$$

Axiom S (Sub-multiplicativity) $\forall \mathbf{x}, \mathbf{y}, P(\mathbf{x} \square \mathbf{y}) \leq P(\mathbf{x})+P(\mathbf{y})$.

Axiom S can be interpreted as saying that averaging (in the multiplicative sense) two populations does not magnify the extent of poverty (i.e. the share of the poor within the global population), nor its intensity (i.e. the individual deprivation suffered from each individual), above the sum of the indexes of the subpopulations. Since $x$ and $y$ are vectors of the same dimension, they correspond to populations of the same size. Hence, this axiom is a weak version of the subgroup additive decomposability applied to populations of equal size.

Axiom PH (Positive Homogeneity) : $\forall \mathbf{x} \in \mathbb{R}_{++}^{K N}, \forall \lambda \geq 0, P\left(\mathbf{x}^{\lambda}\right) \leq \lambda P(\mathbf{x})$.

Axiom S implies that $P\left(\mathrm{x}^{n}\right) \leq n P(\mathbf{x})$ for every $x$ and every integer $n$. Axiom PH extends this property to any non-negative number.

Axiom M (Monotonicity): $P(\mathbf{x}) \leq P(\mathbf{y}) \forall \mathbf{y} \leq \mathbf{x}$.

The aim of the last axiom is to avoid trivial constant indexes.

By analogy with Artzner et al. (1999), a poverty index that satisfies Axioms HI, S, $\mathrm{PH}, \mathrm{M}$ and $\mathrm{NT}$ is said to be coherent.

Similarly to the anonymity axiom for $\mathcal{E}$, the next one is not needed for the characterization of coherent poverty measures, but will prove useful.

Axiom A (Anonymity): Let $\mathbf{x}=\left(\mathbf{x}_{1}, . ., \mathbf{x}_{n}\right) \in \mathbb{R}_{++}^{K N}$ and $\sigma(\mathbf{x})=\left(\mathbf{x}_{\sigma(1)}, \ldots, \mathbf{x}_{\sigma(n)}\right) \in$ $\mathbb{R}_{++}^{K N}$ the vector obtained after having permuted its individual components through the permutation $\sigma \in \mathcal{S}_{n}$. Then, $P(\mathbf{x})=P(\sigma(\mathbf{x}))$.

Proposition 2. (i) If a poverty index, $P(\cdot)$, is coherent, then its poverty exit set, $\mathcal{E}_{P}$, defined by 4, verifies Axioms 1-4 and is closed. Moreover, $P(\cdot)=P_{\mathcal{E}_{P}}(\cdot)$.

(ii) Conversely, if a set, $\mathcal{F}$, satisfies Axioms 1-4, then $P_{\mathcal{F}}$ is coherent, and

$$
\mathcal{E}_{P_{\mathcal{F}}}=\overline{\mathcal{F}} 12
$$

(iii) $\mathcal{E}$ verifies the Anonymity axiom if, and only if, $P$ does.

\footnotetext{
$12 \overline{\mathcal{F}}$ is the topological closure of $\mathcal{F}$.
} 
Proof. (i) 1) $P_{\mathcal{E}}(\mathbf{1})=0$ and Monotonicity imply that $\mathcal{E}$ verifies Axiom 1.

2) If $\mathbf{x}<<\mathbf{1}$, Monotonicity implies $P_{\mathcal{E}}(\mathbf{x}) \geq 0$. However, we can find $\alpha>0$ such that $x \square \mathbf{z}^{\alpha}<<0$, so that $P_{\mathcal{E}}\left(x \square \mathbf{z}^{\alpha}\right) \geq 0$. HI then implies that $\alpha \leq 0$, which is a contradiction. Thus, $\mathcal{E}_{P}$ verifies Axiom 2 .

3) Axioms $\mathrm{S}$ and $\mathrm{PH}$ imply that $\mathcal{E}_{P}$ is multiplicatively convex.

4) If $x \in \mathcal{E}_{P}$, this yields: $P\left(x^{\lambda}\right) \leq \lambda P(x) \leq 0$ for all $\lambda \geq 1$. Consequently, $\mathcal{E}_{P}$ is a multiplicative cone.

5) Axioms $\mathrm{PH}$ and $\mathrm{S}$ imply that the function $x \ni \mathbb{R}_{++}^{K N} \mapsto P(\exp (x))$ is convex, and hence continuous. Consequently, $x \mapsto P(x)$ itself must be continuous, so that $\mathcal{E}_{P}$ is closed.

(ii) 0) Axioms 2 and 3 ensure that $P_{\mathcal{F}}$ is well-defined.

1) $\inf \left\{\tau \in \mathbb{R} \mid \mathbf{x} \square \mathbf{z}^{\tau+\alpha} \in \mathcal{E}\right\}=\inf \left\{\tau \in \mathbb{R} \mid \mathbf{x} \square \mathbf{z}^{\tau} \in \mathcal{E}\right\}-\alpha$, which proves HI.

2) Suppose that $\mathbf{x} \square \mathbf{z}^{\lambda}$ and $\mathbf{y} \square \mathbf{z}^{\beta}$ both belong to $\mathcal{E}$. Axiom 3 implies that $\left(\mathbf{x} \square \mathbf{z}^{\lambda}\right)^{\frac{1}{\alpha}}$ and $\left(\mathbf{y} \square \mathbf{z}^{\beta}\right)^{\frac{1}{1-\alpha}}$ also belong to $\mathcal{E}$ for every $\alpha \in[0,1)$. Axiom 2 then implies that $(\mathbf{x} \square \mathbf{y}) \square \mathbf{z}^{\alpha+\beta}=\left(\mathbf{x} \square \mathbf{z}^{\lambda}\right) \square\left(\mathbf{y} \square \mathbf{z}^{\beta}\right) \in \mathcal{E}$. This proves the multiplicative convexity.

3) Suppose $\mathbf{x} \leq \mathbf{y}$ and $\mathbf{x} \square \mathbf{z}^{\lambda} \in \mathcal{E}$. Then, $\mathbf{y} \square \mathbf{z}^{\lambda} \geq \mathbf{x} \square \mathbf{z}^{\lambda}$, so that, by Axiom 1, $\mathbf{y} \square \mathbf{z}^{\lambda} \in \mathcal{E}$. The monotonicity of $P$ follows.

4) If $m \geq P_{\mathcal{E}}(\mathbf{x})$, then, $\mathbf{x} \square \mathbf{z}^{m} \in \mathcal{E}$, hence, $\forall \lambda>0, \quad \mathbf{x}^{\lambda} \square \mathbf{z}^{\lambda m}=\left(\mathbf{x} \square \mathbf{z}^{m}\right)^{\lambda} \in \mathcal{E}$. Therefore, $P_{\mathcal{E}}\left(\mathbf{x}^{\lambda}\right) \leq \lambda m$.

5) $\forall \mathbf{x} \in \mathcal{F}, \quad P(\mathbf{x}) \leq 0$. Thus, $\mathcal{F} \subset \mathcal{E}_{P_{\mathcal{F}}}$.

\subsection{Properties of coherent multidimensional poverty measures}

\subsubsection{A representation theorem and ordinality}

We now provide a full characterization of the whole family of coherent poverty exit indexes. For this purpose, let us define a weighted geometric average. Given any vector in the unit simplex, $\pi \in \Delta_{+}^{K N}:=\left\{p \in \mathbb{R}_{+}^{K N} \mid \sum_{k, h} p_{k, h}=1\right\}$, the $\pi$-geometric average, $G^{\pi}(\cdot)$, is defined by:

$$
G^{\pi}(x):=\prod_{k, h} x_{k h}^{\pi_{k, h}}
$$

Proposition 3. The index $P$ is coherent if, and only if, there exists a family, $\mathcal{P} \subset \Delta_{+}^{K N}$, of weight vectors, such that

$$
P(\mathbf{x})=-\inf \left\{\frac{\ln \left(G^{\pi}(\mathbf{x})\right)}{\ln \left(G^{\pi}(\mathbf{z})\right)} \mid \pi \in \mathcal{P}\right\}
$$


Proof. The "if" part is immediate. The "only if" part can be deduced from Proposition 2.1 in Huber (1981), and can be stated as a consequence of the bipolar theorem in linear duality theory. Consider the set

$$
C:=\left\{\mathbf{x} \in \mathbb{R}^{K N} \mid \mathbf{x}_{h k}=\ln \left(\mathbf{y}_{h k}\right) \text { for some } \mathbf{y} \in \mathcal{E}\right\} .
$$

It follows from Axioms 3 and 4, together with the closedness of $\mathcal{E}$, that $C$ is a convex and closed cone in $\mathbb{R}^{K N}$. Thus, its polar cone

$$
C^{\circ}:=\left\{\alpha \in \mathbb{R}_{+}^{K N} \mid \sum_{h k} \alpha_{h k} x_{h k} \geq 0 \forall x \in C\right\}
$$

is also a convex and closed cone in $\mathbb{R}_{+}^{K N}$. The bipolar theorem implies that

$$
C=\left\{x \in \mathbb{R}^{K N} \mid \sum_{h, k} \pi_{h k} x_{h k} \geq 0 \forall \pi \in \mathcal{P}\right\},
$$

where $\mathcal{P}:=\Delta_{+}^{K N} \cap C^{\circ}$. We deduce from (5) that $\ln \mathbf{x}+P(\mathbf{x}) \ln \mathbf{z} \in C$, for every $\mathbf{x} \in \mathbb{R}_{++}^{K N}$. Thus, $\forall \pi \in \mathcal{P}, \sum_{h, k} \pi_{h k}\left(\ln \mathbf{x}_{h k}+P(\mathbf{x}) \ln \mathbf{z}_{h k}\right) \geq 0$. Therefore,

$$
P(\mathbf{x}) \sum_{h, k} \pi_{h, k} \ln \mathbf{z}_{h k} \geq-\sum_{h, k} \pi_{h k} \ln \mathbf{x}_{h k} \quad \forall \pi \in \mathcal{P} .
$$

Hence,

$$
P(\mathbf{x}) \geq \sup _{\pi}-\frac{\ln \left(\prod_{h k} \mathbf{x}_{h k}^{\pi_{h k}}\right)}{\ln \left(\prod_{h k} \mathbf{z}_{h k}^{\pi_{h k}}\right)}=-\inf \left\{\frac{\ln \left(G^{\pi}(\mathbf{x})\right)}{\ln \left(G^{\pi}(\mathbf{z})\right)} \mid \pi \in \mathcal{P}\right\} .
$$

Conversely, we deduce from Axiom 2 that $\ln \mathbf{x}+P(\mathbf{x}) \ln \mathbf{z}+\ln \varepsilon \notin C$ for every $\mathbf{x} \in \mathbb{R}_{++}^{K N}$ and every $0 \ll \varepsilon \ll \mathbf{1}$. Therefore, $\forall \pi \in \mathcal{P}, \sum_{h, k} \pi_{h k}\left(\ln \mathbf{x}_{h k}+P(\mathbf{x}) \ln \mathbf{z}_{h k}+\ln \varepsilon\right)<0$. It follows that

$$
P(\mathbf{x} \square \varepsilon)<-\inf \left\{\frac{\ln \left(G^{\pi}(\mathbf{x})\right)}{\ln \left(G^{\pi}(\mathbf{z})\right)} \mid \pi \in \mathcal{P}\right\} .
$$

The equality follows by continuity of $P(\cdot)$.

\section{Examples}

a) The "utilitarian case" corresponds to $\mathcal{P}=\{((1 / K N, \ldots, 1 / K N)\}$.

b) The "Rawlsian" case corresponds to $\mathcal{P}=\Delta_{+}^{K N}$.

Figure 1 provides an illustration of the typical geometry of $\mathcal{E}$. 


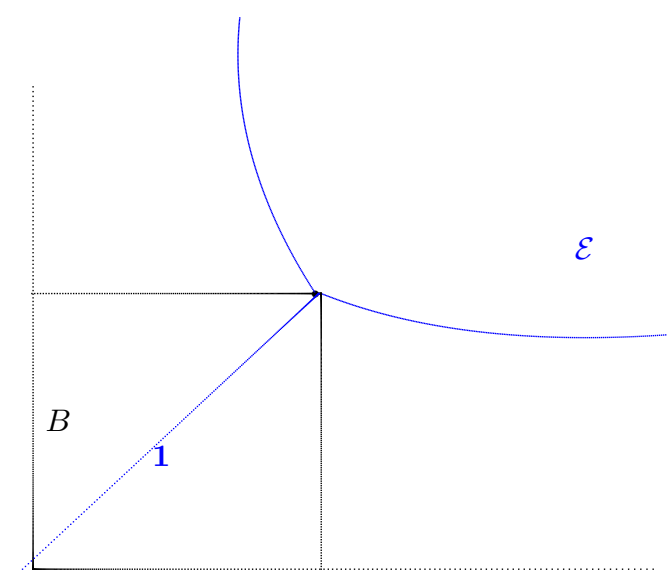

Fig 1. A piecewise smooth poverty exit set

Observe that, in general, the frontier of the set $\mathcal{E}$ need not be smooth, as there is typically a kink at $\mathbf{1}$. The "utilitarian" case corresponds to the situation where the two branches of hyperbola coincide with the hypercurve: $\prod_{h, k} \mathbf{x}_{h, k}=$ constant. This is a unique case where the boundary of $\mathcal{E}$ is a smooth submanifold. The larger the set $\mathcal{P}$, the smaller the subset $\mathcal{E}$. Finally, the Rawlsian case corresponds with the situation where $\mathcal{E}$ coincides with the affine non-negative orthant:

$$
\mathcal{E}=\mathbf{1}+\mathbb{R}_{+}^{K N}
$$

Notice that weights in $\mathcal{P}$ can differ across both individuals and dimensions. When $P$ (or, equivalently, $\mathcal{E}$ ) verifies anonymity, the set of weights, $\mathcal{P}$, reduces to weights over dimensions. The weighted geometric average now becomes:

$$
G^{\hat{\pi}}(x):=\prod_{k, h} x_{k h}^{\frac{\hat{\pi}_{k}}{N}} \quad \forall \hat{\pi} \in \hat{\mathcal{P}} \subset \Delta_{+}^{K} .
$$

Corollary 1. The index $P$ is coherent and anonymous if, and only if, there exists a family, $\hat{\mathcal{P}} \subset \Delta_{+}^{K}$, of weights over dimensions such that

$$
P(\mathbf{x})=-\inf \left\{\frac{\ln \left(G^{\pi}(\mathbf{x})\right)}{\ln \left(G^{\pi}(\mathbf{z})\right)} \mid \pi \in \hat{\mathcal{P}}\right\} .
$$

Thanks to Theorem 3, whether it is anonymous or not, a coherent index $P$ can also easily be shown to be ordinal in the following sense.

Ordinality. A measure, $Q$, is said to be ordinal if the following holds. Given some $N \times K$-matrix $\Lambda=\left(\lambda_{j j}\right) \in \mathcal{M}_{N \times K \times K}\left(\mathbb{R}_{++}\right)$, and given also a social status matrix $y \in \mathcal{M}_{N \times K}\left(\mathbb{R}_{++}\right)$, and a cut-off vector, $\mathbf{z} \in \mathbb{R}_{++}^{K N}$, there exists some $\lambda \in \mathbb{R}$ which depends only upon $\Lambda$, such that:

$$
Q(y ; \mathbf{z})+\lambda=Q(y \square \Lambda ; \mathbf{z} \star \Lambda),
$$


where $y \square \Lambda$ is the $N \times K$-matrix with entry $(y \square \lambda)_{i j}:=y_{i j} \Lambda_{i j}$, and $\mathbf{z} \star \Lambda$ is the $N K$-vector with entry $(\mathbf{z} \star \Lambda)_{n k}:=\mathbf{z}_{n k} \Lambda_{n k}$.

An example will easily illustrate how this abstract property solves several problems related to ordinal data. Consider the question: "Which kind of toilet facility does your household have?", together with three possible answers:

a. "Open defacation field."

b. "Shared flush."

c. "Private flush."

Of course, the metric between each one of these answers does not have any sensible meaning. To circumvent this issue, it suffices to capture this question through two dimensions, each of which accept two answers, $\{a, b\}$ and $\{a, c\}$, which are captured by two variables $\{\alpha, \beta\} \subset \mathbb{R}$ and $\{\alpha, \gamma\} \subset \mathbb{R}$, respectively, with $\alpha<\beta<\gamma$. Ordinality then ensures that the choice of $(\alpha, \beta, \gamma)$ does not matter.

Going back to coherent poverty measures, it is straightforward for any $x \in \mathbb{R}_{++}^{K N}$ and any $\Lambda$ as above, $x \Lambda / \mathbf{z} \Lambda=x / \mathbf{z}$. Thus, as we only deal with normalized achievements, any Multidimensional Poverty Index is ordinal.

\subsubsection{Who is poor?}

In this subsection, we confine ourselves to the subfamily of anonymous coherent poverty indexes. Consequently, $P$ is associated with a set, $\mathcal{P} \subset \Delta_{+}^{k}$, of $K$-dimensional vector of weights, $\pi=\left(\pi_{k}\right)_{k}$ - one for each dimension-belonging to the unit simplex.

We now provide an answer to the question "who is poor?". Regarding this issue, two kinds of approach have been explored in the literature ${ }^{13}$ The "union" approach regards a person who is deprived in one dimension as being poor at the multidimensional level. This is usually acknowledged to be overly inclusive and leads to exaggerate estimates of poverty. In contrast, the "intersection" approach requires a person to be deprived in all dimensions before being considered poor. This is often considered too constricting, and may lead to untenably low estimates of poverty. We now show that the natural definition of a poor person that follows from our approach leads to an endogenous determination that is always strictly less inclusive than the "union" approach and weakly more inclusive than the "intersection" approach. Therefore, it lies somewhere between these two extremes, and in fact, it turns out that only the Rawlsian case coincides with the "intersection" viewpoint.

Two examples will help to identify how the determination of poor persons occurs in our setting. Consider the case where $N=1$; i.e., the population consists of a single person. Then, clearly, this single person, $i$, will be poor whenever the population is so; i.e., when $P\left(\mathbf{x}_{i}\right)<0$. Next, suppose that the population is made of $n$ identical people. Again, each person will be poor if the population is so; i.e., if, and only if, $\prod_{k} x_{i}^{\pi_{k}}<\prod_{k} \mathbf{z}_{i}^{\pi_{k}}$ for every $\pi \in \mathcal{P}{ }^{14}$

\footnotetext{
${ }^{13}$ See, e.g., Alkire and Foster (2008) and Villar (2010).

${ }^{14}$ Notice that, here, $x$ is not normalized.
} 
It is this latter condition that we adopt as a definition. Indeed, a simple continuity argument explains why no other choice can be made. Take $0 \ll \varepsilon \ll \mathbf{1}$; one has $x \square \varepsilon$ poor and $G^{\pi}(\mathbf{x})<1$ for any $\pi$. However, $\lim _{\varepsilon \rightarrow 1} G^{\pi}(\mathbf{x})=1^{-}$. Thus, no population such that $G^{\pi}(\mathbf{x})<1$ can be considered as non-poor.

Definition 1. Given a coherent poverty index, $P$, associated with a set of weights, $\mathcal{P} \subset$ $\Delta_{+}^{K N}$, a person, $i$, is poor whenever

$$
\prod_{k} \mathbf{x}_{i, k}^{\pi_{k}}<\prod_{k} \mathbf{z}_{k}^{\pi_{k}} \forall \pi \in \mathcal{P}
$$

or, equivalently, when

$$
\sup _{\pi \in \mathcal{P}} G^{\pi}\left(\mathbf{x}_{i}\right)<1 .
$$

In the "utilitarian" case (where $\mathcal{P}$ reduces to the uniform singleton), this definition coincides with the one introduced by Villar (2010).

As an illustration, let us consider a society according to two dimensions. The poor are all individuals who fall strictly below the two branches of hyperbola:

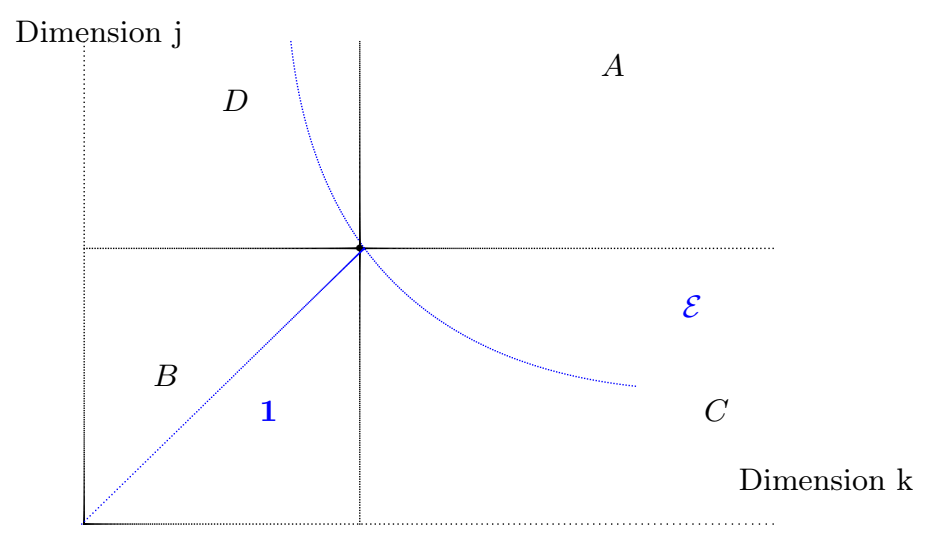

Fig 2. Who is poor?

The set $\mathcal{E}$ is always larger than the one defined by the intersection approach, and is always contained in the one provided by the union approach. The Rawlsian case, here, coincides with the intersection approach. 


\section{$5 \quad$ Empirical applications}

To compute the RCI from the Nigerian and Afrobarometer databases, we used the questions and cutoffs presented in Tables 5 and 10, respectively. We computed each dimensional index using arithmetic means on the components, following equation 1 . Then, we computed three versions of the RCI, each one of which was a specific element of the family of indexes characterized in the previous section.

The specificity of our data led us to adapt the axiomatic developed supra. Indeed, with the choice of metrics we made at the components level $\left(c_{i, j} \in\{0,1\}\right.$, see 3.3.1), two of our hypotheses on dimensions could be violated: the assumption that all variables be strictly positive and the assumption that all thresholds be strictly superior to 1 (see 4.2), so we could have faced the risk of computing the log of 0 and/or dividing by 0 .

Moreover, in order to follow Walzer's approach (Walzer, 1983), we wanted to implement a particular version of the geometric mean, namely $G(x)=1-\prod_{i, k}\left(1-x_{i k}\right)^{\pi_{i k}}$. This specification, combined with our choices of cutoffs, implies that the mere existence of a non-deprived individual in one dimension yields a geometric mean equal to 1 , which is quite problematic from a comparative perspective.

The next subsection deals with the choices we made to overcome these two issues, and presents the three specific indexes we used in our empirical work. We then present the results of our estimations in the Niger Delta, Nigeria; and on the Afrobarometer databases.

\subsection{Characterization of our empirical indexes}

\subsubsection{Methodological choices}

Given our metrics, and the particular kind of indexes we want to compute, we define the endogenous set of poor as the subset of people who have a score strictly inferior to 1 in all dimensions - or, more precisely, the dimensions pondered by a positive weight for at least one probability measure $\pi \in \mathcal{P}$. 15 This is consistent with Proposition 3 of the previous section. Obviously, this means that, while being continuous with respect to achievements, our multidimensional measure is not continuous with respect to (any topology on the space of) probability measures in the unit simplex $\Delta^{K}:=\left\{\pi \in \mathbb{R}_{+}^{K} \mid \sum_{k} \pi^{k}=1\right\}$. Moreover, a person who has a score of 1 in at least one dimension associated with a strictly positive weight will get the same global score as a person who has a score of 1 in all dimensions. Since the latter has no deprivation and hence is clearly non-poor, for continuity reasons, the former should also be considered as non-poor according to the family of weights we use. This is consistent with the Walzerian theory of justice underlying our approach: for a person to be non-poor, it "suffices" that

\footnotetext{
${ }^{15}$ In other words, if someone has a score equal to the threshold, 1 , in dimension $k$ and a score strictly inferior to 1 in all the other dimensions, they will be considered as non-deprived if at least one probability measure, $\pi$, within the family $\mathcal{P}$ involved in the definition of $P(\cdot)$ puts a positive weight on dimensionk. However, the individual will be viewed as deprived if none of the probabilities, $\pi$, under scrutiny has a non-zero weight associated with dimension $k$.
} 
they succeed in being non-deprived in at least one relevant social sphere. Each social sphere is captured by means of our dimensions. Relevance is measured through the family of weights, $\mathcal{P}$.

Let $N_{p}^{\pi}$ denote the number of poor that results from this definition. Since none of the dimensional weights we are going to consider in the rest of this paper are null, the set of poor is the same for all our families of weights. Thus, we can identify $N_{p}^{\pi}:=N_{p}$. The share of poor people in the population, $N_{p} / N$, will be used to measure the extent of poverty.

We then compute our indexes on the subset of poor people. This is coherent with the axioms, since it corresponds to the case where we apply the following family of weights: $\mathcal{P}=\left(\pi_{p}, \pi_{\bar{p}}\right)$, where poor people are indexed by $p$ and non-poor by $\bar{p}$, with $\pi_{\bar{p}}=0$. Different kinds of weights (anonymous or "Maximin" in the following examples) can then be applied within the set of poor as long as the family, $\pi_{p}$, verifies itself the conditions on weight families.

The ratio $N_{p} / N$, and our family of indexes, measure the extent and the intensity of poverty, respectively.

We can easily get one single index that summarizes the two pieces of information by multiplying them, following Alkire and Foster (2008). We present these kinds of measures here, in addition to our separate measures of extent and intensity. Nevertheless, it should be borne in mind that the synthetic indexes obtained via multiplication are not Coherent Poverty Indexes as defined in the axioms ${ }^{16}$

\subsubsection{Relational Capability Index and Relational Deprivation Index}

Until now, we have only introduced the RCI, which increases with the level of functionings. For comparability reasons, since the main poverty indexes such as the MPI are presented in the opposite way (i.e. they increase with the level of deprivation), and in order to respect the axiomatic viewpoint, which is also written in terms of deprivations, we decided to create a second index, which can be calculated from a simple transformation of the RCI. We called this the "Relational Deprivation Index" (RDI). The next paragraph explains how the RCI and RDI are computed in the specific case of our Nigerian and Afrobarometer data, and how to pass from one to the other in each of the specifications.

\subsubsection{Our Indexes}

Utilitarian indexes We computed three versions of the utilitarian index presented above - i.e. the index we obtain via uniform weighting of both dimensions and individuals-

\footnotetext{
${ }^{16}$ Indeed, the set of poor itself is not a Coherent Poverty Index since it only consists of counting the poor; i.e. computing the arithmetic mean of a dummy equal to 1 if the individual is poor, and 0 if they are not. Multiplying a Coherent Poverty Index with such a measure would yield an index which clearly has no reason to verify the axioms on Coherent Poverty Indexes.
} 
the arithmetic means $\left(R C I_{a}\right.$ and $\left.R D I_{a}\right)$, the geometric means $\left(R C I_{g}\right.$ and $\left.R D I_{g}\right){ }^{17}$, and our "utilitarian" coherent capability indexes $\left(R C I_{u}\right.$ and $\left.R D I_{u}\right)$, using the following characterizations:

$$
\begin{array}{lll}
R C I_{a}=\frac{1}{3 N_{p}} \sum_{i=1}^{N_{p}} \sum_{k=1}^{3} x_{i, k} & R D I_{a}=1-R C I_{a} \\
R C I_{g}=1-\prod_{i=1}^{N_{p}} \prod_{k=1}^{3}\left(1-x_{i, k}\right)^{\frac{1}{3 N_{p}}} & R D I_{g}=1-R C I_{g} \\
R C I_{u}=-\ln \left[\prod_{i=1}^{N} \prod_{k=1}^{3}\left(1-x_{i, k}\right)^{\frac{1}{3 N_{p}}}\right] & R D I_{u}=-\ln \left[1-\prod_{i=1}^{N} \prod_{k=1}^{3}\left(1-x_{i, k}\right)^{\frac{1}{3 N_{p}}}\right]
\end{array}
$$

The construction of our "utilitarian" coherent capability indexes deserves specific comment. Indeed, they are computed from the log of the geometric indexes. However, in order to express them in the same way as the arithmetic and geometric means, and to obtain positive numbers, we use the geometric $R C I$ to compute the utilitarian $R D I$, and vice versa: $R C I_{u}=-\ln \left(R D I_{g}\right)$ and $R D I_{u}=-\ln \left(R C I_{g}\right)^{18}$

Weighted indexes We present two forms of weighted indexes, using the family of dimensional weights $\mathcal{P}=((1 / 2,1 / 4,1 / 4),(1 / 4,1 / 2,1 / 4),(1 / 4,1 / 4,1 / 2))$ and the general formula:

$R C I_{w}=-\sup _{i, \pi}\left[\ln \prod_{i=1}^{N_{p}} \prod_{k=1}^{3}\left(1-x_{i, k}\right)^{\pi_{k, i}}\right]$ and $R D I_{w}=-\inf _{i, \pi}\left[\ln \left(1-\prod_{i=1}^{N_{p}} \prod_{k=1}^{3}\left(1-x_{i, k}\right)^{\pi_{k, i}}\right)\right]$

We also tested two other families of dimensional weights, which we do not present here since the conclusions remained unchanged ${ }^{19}$.

Our "Anonymous" indexes $\left(R C I_{d}\right.$ and $\left.R D I_{d}\right)$ consider all individuals as equally important, which boils down to applying a uniform set of weights $\left(1 / N_{p}, \ldots, 1 / N_{p}\right)$ for individuals and only using dimensional weights. On the contrary, our "Rawlsian" indexes $\left(R C I_{r}\right.$ and $\left.R D I_{r}\right)$ use Dirac measures on $i$ in addition to the weights on $k$. They allow us to study the evolution of the poorest individuals of our sample, illustrating Rawls's definition of the "Maximin" principle.

\footnotetext{
${ }^{17}$ Indeed, the arithmetic mean is not a Coherent Poverty Index as defined in this paper. Nonetheless, we computed it for comparability reasons with other indexes, such as the MPI. The geometric mean is an intermediate step before computing the final utilitarian index.

${ }^{18}$ Our geometric indexes are included in ]0,1]; hence, taking the log of these indexes yields a negative number. This is why we take the opposite of the log. But since $\ln$ is an increasing function, $-\ln$ is decreasing and we have to switch $R C I$ and $R D I$ to obtain an outcome that reads in the same way as the geometric mean.

${ }^{19}$ More precisely, we tested $\widehat{\mathcal{P}}=((2 / 3,1 / 3,0),(1 / 3,2 / 3,0),(2 / 3,0,1 / 3),(1 / 3,0,2 / 3),(0,1 / 3,2 / 3)$, $(0,2 / 3,1 / 3))$ and $\widetilde{\mathcal{P}}=((1 / 2,1 / 3,1 / 6),(1 / 2,1 / 6,1 / 3),(1 / 3,1 / 2,1 / 6),(1 / 3,1 / 6,1 / 2),(1 / 6,1 / 3,1 / 2)$, $(1 / 6,1 / 2,1 / 3))$. One should bear in mind, however, that to compute $\widehat{\mathcal{P}}$ we would have to re-define the set of poor since we set the weight of one dimension to 0 , and all people who were non-poor according to this dimension only should now be considered as poor.
} 


$$
\begin{array}{ll}
R C I_{d}=-\sup _{\pi \in \mathcal{P}}\left[\ln \prod_{i=1}^{N_{p}} \prod_{k=1}^{3}\left(1-x_{i, k}\right)^{\pi_{k} / N_{p}}\right] & R D I_{d}=-\inf _{\pi \in \mathcal{P}}\left[\ln \left(1-\prod_{i=1}^{N_{p}} \prod_{k=1}^{3}\left(1-x_{i, k}\right)^{\pi_{k} / N_{p}}\right)\right] \\
R C I_{r}=-\sup _{\substack{\pi \in \mathcal{P} \\
i \in\left\{1, \ldots, N_{p}\right\}}}\left[\ln \prod_{k=1}^{3}\left(1-x_{i, k}\right)^{\pi_{k, i}}\right] \quad R D I_{r}=-\inf _{\substack{\pi \in \mathcal{P} \\
i \in\left\{1, \ldots, N_{p}\right\}}}\left[\ln \left(1-\prod_{k=1}^{3}\left(1-x_{i, k}\right)^{\pi_{k, i}}\right)\right]
\end{array}
$$

Our three versions of the RCI (respectively RDI), $R C I_{u}, R C I_{d}, R C I_{r}$ (respectively $R D I_{u}, R D I_{d}, R D I_{r}$ ), along with the share of non-poor, $1-N_{p} / N$ (respectively the share of poor $N_{p} / N$ ), give a first overview of the types of indicators that the axioms can yield in terms of relational capabilities (respectively deprivations). Multiplying the two elements allows us to synthetize the information regarding extent and intensity into one single index.

Indeed, many other elements of the family should be tested; e.g. those that use the family of weights based on Dirac measures of dimensions. We aim to focus on this in future work.

\subsection{Empirical application: the relational impact of oil extraction in the Niger Delta}

\subsubsection{Presentation of the Nigerian project}

The research has been carried out by CODEV ${ }^{20}$ in Nigeria since 2007 on the societal commitment of Total in the Niger Delta aims to study, through the "Poverty Exit Index" (PEI) and the RCI, the impact of the company's presence for local communities in terms of material living conditions and social network quality, in a context of corruption, clientelism and rising inequalities.

Our PEI is based on the same dimensions as the Multidimensional Poverty Index presented above (see Table 3): education, health and standards of living. These dimensions break down into several components ( 8 in total).

We actually computed two versions of this index. The first, PEI1, was inspired by Muhammad Yunus's suggestion to assess the poverty exit situation for those who have utilized microcredit programs. PE1 uses uniform weighting: each component is weighted by $1 / 8$, regardless of the number of components in its dimension. As a second attempt, following the creation of the MPI by UNDP and OPHI in 2010, we developed a revised version of our index, PE2. This time, we attributed equal weights (of $1 / 3$ ) to each dimension, and weighted each component by the reciprocal of the number of components within the dimension. For instance, the "Health" dimension includes three components,

\footnotetext{
${ }^{20} \mathrm{CODEV}$, which stands for Companies and Development, is a research program within ESSEC IRENE. It aims to study the extent to which, and under what criteria, companies can contribute to the sustainable development of the areas in which they operate, especially in regions of great poverty and social fragility. For more information, see https://sites.google.com/a/essec.edu/ essec-irene-english/presentation
} 
each of which weighs $1 / 3 \times 1 / 3=1 / 9$ in the index.

The RCI we use in this section is the one described above (see Table 5 for a definition of the specific cutoffs we used in Nigeria).

\begin{tabular}{|c|c|c|c|}
\hline Dimension & Component & Labels & Cutoff \\
\hline \multirow{4}{*}{$\begin{array}{l}\text { Integration } \\
\text { to networks } \\
\text { (IN) }\end{array}$} & $\begin{array}{l}\text { Employment } \\
\text { status }\end{array}$ & empstat & $\begin{array}{l}1 \text { if working/student } \\
0 \text { if otherwise }\end{array}$ \\
\hline & $\begin{array}{l}\text { Access to } \\
\text { transportation }\end{array}$ & transport & $\begin{array}{l}1 \text { if good, } \\
0 \text { if otherwise }\end{array}$ \\
\hline & $\begin{array}{l}\text { Access to } \\
\text { telecommunications }\end{array}$ & tele & $\begin{array}{l}1 \text { if owns a phone } \\
0 \text { if not }\end{array}$ \\
\hline & $\begin{array}{l}\text { Access to } \\
\text { information }\end{array}$ & information & $\begin{array}{l}1 \text { if listens to radio/reads newspaper/watches TV every day } \\
0 \text { if else }\end{array}$ \\
\hline \multirow{5}{*}{$\begin{array}{l}\text { Private } \\
\text { relations } \\
(\mathrm{PR})\end{array}$} & $\begin{array}{l}\text { Number of people } \\
\text { in the household }\end{array}$ & hhsize & $\begin{array}{l}1 \text { if lives with other people } \\
0 \text { if lives alone }\end{array}$ \\
\hline & Family ties & famties & $\begin{array}{l}1 \text { if perceives that at least one family member loves them } \\
0 \text { if otherwise }\end{array}$ \\
\hline & $\begin{array}{l}\text { Number of } \\
\text { close friends }\end{array}$ & closefriends & $\begin{array}{l}1 \text { if at least one } \\
0 \text { if none }\end{array}$ \\
\hline & Financial support & finfriend & $\begin{array}{l}1 \text { if can borrow from at least } 1 \text { person outside the household } \\
0 \text { if not }\end{array}$ \\
\hline & $\begin{array}{l}\text { Trust/unity } \\
\text { in the community }\end{array}$ & trustcomm & $\begin{array}{l}1 \text { if social unity of the village is defined as a partnership, } \\
0 \text { if otherwise }\end{array}$ \\
\hline \multirow{5}{*}{$\begin{array}{l}\text { Civic } \\
\text { commitment } \\
(\mathrm{CV})\end{array}$} & Membership & membership & $\begin{array}{l}1 \text { if member of at least one group } \\
0 \text { if not }\end{array}$ \\
\hline & Collective action & collective & $\begin{array}{l}1 \text { if the group works with other groups in the community } \\
0 \text { if not }\end{array}$ \\
\hline & Vote & vote & $\begin{array}{l}1 \text { if voted at least once in the last } 6 \text { elections } \\
0 \text { if otherwise }\end{array}$ \\
\hline & Solidarity & solidarity & $\begin{array}{l}1 \text { if participates in community activities regularly/occasionally } \\
0 \text { if once or never }\end{array}$ \\
\hline & Trust in others & trustother & $\begin{array}{l}1 \text { if thinks most people can be trusted } \\
0 \text { if not }\end{array}$ \\
\hline
\end{tabular}

Table 5: RCI definition in Nigeria

The field work was conducted in the two Nigerian regions of Onelga and Eastern Obolo. The first has been benefiting from greater corporate engagement since Total launched an upgrade project in this region, which resulted in more jobs and contracts compared to in Eastern Obolo, where just a few projects have been supported by oil companies since 2008.

In Nigeria, oil production dates back to 1958. The oil sector is the greatest contributor to the national budget - up to $77 \%$ of revenues in 2010 (IMF, 2011) - but early in the last decade, Nigeria ranked as either the most corrupt or the second most corrupt country (Transparency International, 2004) in the Corruption Perception Index. Corruption deprives citizens of resources designed for development, and allows a handful of the elite to confiscate common resources, resulting in acute inequalities. Oil companies 
may be seen as paying huge taxes that never reach local communities, thereby reinforcing inequalities within the society.

Since the riots of the 1990s (Human Rights Watch, 2005), the government has asked oil companies to directly fund socio-economic programs within communities. Since then, company relations with communities are managed under Memoranda of Understanding (MoUs) signed under the supervision of the government. MoUs are non-legally-binding commitments towards host communities, wherein companies agree to spend a share of their revenue, on road construction, health and educational infrastructures, and education; most of these expenditures are tax-deductible. The companies also provide jobs and vocational training opportunities aimed at engaging people in self income-generating activities. In return, communities agree to guarantee peace and an uninterrupted continuation of oil operations, and to participate in the implementation of development projects. In this regard, in 2010 , Shell dedicated $\$ 65 \mathrm{~m}$ to the MoU package, while Total and Chevron contributed $\$ 50 \mathrm{~m}$ each. However, this model raises many issues, mostly related to clientelism and corruption.

Two surveys were led, one in 2008 and one in 2012, in two areas directly and indirectly impacted by oil production: the Onelga Local Government Area, in Rivers State, where Total and Agip have been operating since the 60s; and the Eastern Obolo Local Government Area, in Akwa Ibom State, which is impacted by offshore oil production. In Eastern Obolo, between 2003 and 2009, Total sponsored an NGO, Pro-Natura International, that has set up a Local Development Foundation (EOCDF) aimed at fostering local development. Since 2009, under an MoU signed with Akwa Ibom State, Total has provided funding to the State, which is supposed to be distributed to Eastern Obolo LGA and to other coastal LGAs. The amounts of money spent by Total in Eastern Obolo are very small ( $\$ 350,000$ per year), compared to the $\$ 50 \mathrm{~m}$ spent by the company in its onshore production site in Onelga.

Our surveys enable a comparison between the two areas - onshore (Onelga) and coastal (Eastern Obolo) - as well as a comparison between the communities impacted by different oil companies (Total and Agip) in the onshore area (Onelga). In the two areas, the contribution of local authorities to local development is minimal. The field work aimed to compare the situation in the two areas, in terms of both material wellbeing and relational capabilities, and to see whether the direct funding of oil companies to local communities has contributed to improving the quality of the social fabric. The results concerning the two zones are presented here.

\subsubsection{Results}

The results obtained from the computation of RCI and RDI in Nigeria are presented in Tables 6 and 8 , respectively. Tables 7 and 9 present the synthetic indexes we obtain by multiplying the intensity and the extent of poverty for RCI and for RDI, respectively 21

\footnotetext{
${ }^{21}$ More precisely, in order to obtain indexes that all read the same way, and are increasing with capabilities for RCI and with deprivations for RDI, we compute the synthetic index on RCI by multiplying the share of non-poor by the different RCI indexes, and the synthetic index on RDI by multiplying the
} 


\begin{tabular}{llcccc}
\hline RCI Measure & Notation & $\begin{array}{c}\text { Obolo } \\
\mathbf{2 0 0 8}\end{array}$ & $\begin{array}{c}\text { Obolo } \\
\mathbf{2 0 1 2}\end{array}$ & $\begin{array}{c}\text { Onelga } \\
\mathbf{2 0 0 8}\end{array}$ & $\begin{array}{c}\text { Onelga } \\
\mathbf{2 0 1 2}\end{array}$ \\
\hline Share of poor & $N_{p} / N$ & $24 \%$ & $18 \%$ & $46 \%$ & $28 \%$ \\
Arithmetic mean & $\mathrm{RCI}_{a}$ & 0.62 & 0.67 & 0.56 & 0.69 \\
Geometric mean & $\mathrm{RCI}_{g}$ & 0.67 & 0.71 & 0.62 & 0.72 \\
Utilitarian index & $\mathrm{RCI}_{u}$ & 1.11 & 1.23 & 0.97 & 1.28 \\
Rawlsian index & $\mathrm{RCI}_{r}$ & 0.28 & 0.46 & 0.20 & 0.60 \\
Anonymous index & $\mathrm{RCI}_{d}$ & 1.00 & 1.14 & 0.90 & 1.21 \\
\hline \multicolumn{1}{c}{$N$} & & 620 & 519 & 598 & 486 \\
\hline
\end{tabular}

Table 6: RCI computation for Nigeria

\begin{tabular}{cccccc}
\hline $\begin{array}{c}\text { Synthetic Relational } \\
\text { Capabilities Index }\end{array}$ & $\begin{array}{c}\text { Obolo } \\
\mathbf{2 0 0 8}\end{array}$ & $\begin{array}{c}\text { Obolo } \\
\mathbf{2 0 1 2}\end{array}$ & $\begin{array}{c}\text { Onelga } \\
\mathbf{2 0 0 8}\end{array}$ & $\begin{array}{c}\text { Onelga } \\
\mathbf{2 0 1 2}\end{array}$ \\
\hline Arithmetic & $\mathrm{RCI}_{a} \times\left(1-N_{p} / N\right)$ & 0.471 & 0.552 & 0.304 & 0.500 \\
Geometric & $\mathrm{RCI}_{g} \times\left(1-N_{p} / N\right)$ & 0.509 & 0.584 & 0.334 & 0.522 \\
Utilitarian & $\mathrm{RCI}_{u} \times\left(1-N_{p} / N\right)$ & 0.844 & 1.016 & 0.520 & 0.923 \\
Rawlsian & $\mathrm{RCI}_{r} \times\left(1-N_{p} / N\right)$ & 0.216 & 0.378 & 0.107 & 0.436 \\
Anonymous & $\mathrm{RCI}_{d} \times\left(1-N_{p} / N\right)$ & 0.757 & 0.939 & 0.485 & 0.878 \\
\hline & $N$ & & & & \\
\hline
\end{tabular}

Table 7: Synthetic indexes on the intensity and extent of capabilities 
Four main conclusions can be drawn from these results:

Relational poverty declined in both areas between 2008 and 2012, in terms of extent as well as intensity. In other words, there are fewer poor people (the first lines of Tables 6 and 8 show that the share of the poor decreased by 6 percentage points in Obolo and by 18 percentage points in Onelga), and the capabilities of poor people have increased. This second observation holds no matter which index we consider: for a given area, lines 2 to 6 of Tables 6 and 8 show that all RCI indexes increase, and all RDI indexes decrease, between 2008 and 2012 .

The extent and intensity of poverty were higher in Onelga than in Obolo in 2008 : the share of poor is equal to $46 \%$ in Onelga and $24 \%$ in Obolo at this date, and Tables 6 and 7 show that, whichever version of the RCI we consider, it is higher in Obolo (third column) than in Onelga (fifth column). The reverse observation holds for RDI in Tables 8 and 9, meaning that the deprivations were greater in Onelga than in Obolo in 2008.

The increase of capabilities has been stronger in Onelga than in Obolo during the period under study. The decrease in the share of poor is greater in proportion in Onelga than in Obolo, and the variation in the intensity of poverty between 2008 and 2012 is more pronounced in Onelga, whichever index we consider. In 2012, poor people in Onelga even seem to be slightly less deprived than poor people in Obolo (RDI measures were all higher in Obolo in 2012). Nonetheless, the extent of poverty, as measured by the share of poor people in the population, is still much higher in Onelga than in Obolo.

Our synthetic indexes point out that relational deprivation was still higher in Onelga than in Eastern Obolo in 2012 . Indeed, the previous conclusion allows us to interpret this observation in more detail: among the two components of the synthetic index, poverty extent was higher in Onelga, whereas poverty intensity was higher in Obolo in 2012. What the synthetic index tells us is that the gap in poverty extent more than compensated for the difference in poverty intensity, leading the synthetic index to indicate greater deprivations in Onelga.

It is interesting to point out that the last observation would not be noticable if we were measuring capabilities using simple averages for the whole population; this highlights one of the areas in which our indexes are of particular use.

share of poor by the RDI indexes. 


\begin{tabular}{llcccc}
\hline RDI Measure & Notation & $\begin{array}{c}\text { Obolo } \\
\mathbf{2 0 0 8}\end{array}$ & $\begin{array}{c}\text { Obolo } \\
\mathbf{2 0 1 2}\end{array}$ & $\begin{array}{c}\text { Onelga } \\
\mathbf{2 0 0 8}\end{array}$ & $\begin{array}{c}\text { Onelga } \\
\mathbf{2 0 1 2}\end{array}$ \\
\hline Share of poor & $N_{p} / N$ & $24 \%$ & $18 \%$ & $46 \%$ & $28 \%$ \\
Arithmetic mean & $\mathrm{RDI}_{a}$ & 0.38 & 0.33 & 0.44 & 0.31 \\
Geometric mean & $\mathrm{RDI}_{g}$ & 0.33 & 0.29 & 0.38 & 0.28 \\
Utilitarian index & $\mathrm{RDI}_{u}$ & 0.40 & 0.34 & 0.48 & 0.33 \\
Rawlsian index & $\mathrm{RDI}_{r}$ & 1.39 & 1.00 & 1.71 & 0.79 \\
Anonymous index & $\mathrm{RDI}_{d}$ & 0.46 & 0.39 & 0.52 & 0.35 \\
\hline \multicolumn{1}{c}{$N$} & & 620 & 519 & 598 & 486 \\
\hline
\end{tabular}

Table 8: RDI computation for Nigeria

\begin{tabular}{cccccc}
\hline $\begin{array}{c}\text { Synthetic Relational } \\
\text { Deprivation Index }\end{array}$ & $\begin{array}{c}\text { Obolo } \\
\mathbf{2 0 0 8}\end{array}$ & $\begin{array}{c}\text { Obolo } \\
\mathbf{2 0 1 2}\end{array}$ & $\begin{array}{c}\text { Onelga } \\
\mathbf{2 0 0 8}\end{array}$ & $\begin{array}{c}\text { Onelga } \\
\mathbf{2 0 1 2}\end{array}$ \\
\hline Arithmetic & $\mathrm{RDI}_{a} \times N_{p} / N$ & 0.091 & 0.058 & 0.201 & 0.085 \\
Geometric & $\mathrm{RDI}_{g} \times N_{p} / N$ & 0.079 & 0.051 & 0.176 & 0.077 \\
Utilitarian & $\mathrm{RDI}_{u} \times N_{p} / N$ & 0.096 & 0.060 & 0.221 & 0.090 \\
Rawlsian & $\mathrm{RDI}_{r} \times N_{p} / N$ & 0.335 & 0.175 & 0.789 & 0.219 \\
Anonymous & $\mathrm{RDI}_{d} \times N_{p} / N$ & 0.111 & 0.068 & 0.241 & 0.097 \\
& & & & & \\
\hline
\end{tabular}

Table 9: Synthetic indexes on the intensity and extent of deprivations 


\subsection{Computation of the RDI at a national level using Afrobarometer dataset}

\subsubsection{Presentation of the data}

We compute our RCI and RDI using the Afrobarometer dataset. Afrobarometer is a comparative dataset which aims to measure the social, political and economic environment of several African countries. We use the Afrobarometer Round 4 surveys, which took place in 20 countries ${ }^{22}$ between March 2008 and June 2009. We present in Table 10 the questions and thresholds we used in our index computation. More references on each question are available in the Afrobarometer codebook (ICPSR, 2009).

We test robustness to poverty cutoffs, as recommended by Alkire and Santos (2010). The last two columns of Table 10 present the thresholds we tested at the component level, using a Student test. Considering the whole sample or each country leads to the same results: the differences are non-significant at a $5 \%$ level. Moreover, we ran a Spearman test to compare the second index to the first ranking, and, even though some slight changes occurred in the second ranking, this ranking is no different from the first one. We find a Spearman's $\rho$ of -0.82 , significant at a $1 \%$ level. Hence, our index is robust to poverty cutoffs at the component level. Future work should include testing different dimensional poverty cutoffs.

The results from our tests are not presented in this paper but are available upon request. In the rest of this section, we present results corresponding to the Extensive thresholds (last column of Table 10).

\begin{tabular}{|l|l|l|l|l|}
\hline Dimensions & Components & Code & $\begin{array}{l}\text { Threshold 1 } \\
\text { (Restrictive) }\end{array}$ & $\begin{array}{l}\text { Threshold 2 } \\
\text { (Extensive) }\end{array}$ \\
\hline Integration to network & Employment status & 4,5 & $2,3,4,5$ \\
& Access to transport & Q94 & 1 \\
& Eccess to telecommunications & EA:ROAD & 1 & 4,3 \\
& Access to information & Q 12 B & 4 & 4,3 \\
\hline Private relations & Number of people in the household & ADULT:CT & More than 2 & More than 1 \\
& Family ties & Q84A & 3 & 3 \\
& Close friends, emotional support & Missing & & \\
& Financial support & Missing & & 3,2 \\
& Trust in the community & Q84B & 3 & 3,2 \\
Civic commitment & Membership & Q22A & 3 & $4,3,2$ \\
& Collective action & Q23A & 4 & 1,2 \\
& Vote & Q23D & 1 & 2,3 \\
& Solidarity & Q22B & 3 & Q84C \\
& Trust in others & 3 & 2,3 \\
\hline
\end{tabular}

Table 10: Index dimensions and components

\footnotetext{
${ }^{22}$ Benin, Botswana, Burkina Faso, Cape Verde, Ghana, Kenya, Lesotho, Liberia, Madagascar, Malawi, Mali, Mozambique, Namibia, Nigeria, Senegal, South Africa, Tanzania, Uganda, Zambia, Zimbabwe
} 


\subsubsection{Results}

The results we obtain from the computation of RDI on the Afrobarometer dataset are presented in Tables 11 to 13 . We also computed RCI but do not display the results in the present paper, for comprehensibility. They are available upon request. Table 11 presents the RDI incidence and intensity according to the different versions of the index we defined in section 4 , with the values and rankings for each country. Table 12 confronts the RDI results and rankings with those of material poverty indices: MPI and GDP per capita. Table 13 details the RDI scores and rankings by dimension. Four main results are worth mentioning here.

\begin{tabular}{lcllllll}
\hline & & Share of poor & \multicolumn{5}{c}{ Intensity } \\
\cline { 5 - 7 } Country & $N$ & (Incidence) & Arith. & Geom. & Utilitarian & Anonymous & Rawlsian \\
\hline Benin & 1187 & $77 \%(2)$ & 0.60 & 0.55 & $0.80(1)$ & $0.84(1)$ & $2.91(1)$ \\
Botswana & 1198 & $70 \%(7)$ & 0.56 & 0.51 & $0.71(6)$ & $0.75(5)$ & $2.91(1)$ \\
Burkina Faso & 1181 & $65 \%(9)$ & 0.58 & 0.53 & $0.75(4)$ & $0.83(2)$ & $2.91(1)$ \\
Cape Verde & 1232 & $58 \%(12)$ & 0.54 & 0.49 & $0.67(11)$ & $0.66(15)$ & $2.67(15)$ \\
Ghana & 1199 & $49 \%(17)$ & 0.49 & 0.44 & $0.57(18)$ & $0.60(18)$ & $2.34(19)$ \\
Kenya & 1071 & $55 \%(13)$ & 0.49 & 0.43 & $0.57(18)$ & $0.60(18)$ & $2.91(1)$ \\
Lesotho & 1198 & $78 \%(1)$ & 0.59 & 0.54 & $0.77(2)$ & $0.80(3)$ & $2.91(1)$ \\
Liberia & 1197 & $71 \%(6)$ & 0.55 & 0.49 & $0.68(9)$ & $0.73(8)$ & $2.91(1)$ \\
Madagascar & 1347 & $74 \%(3)$ & 0.58 & 0.54 & $0.77(2)$ & $0.79(4)$ & $2.91(1)$ \\
Malawi & 1181 & $73 \%(4)$ & 0.53 & 0.47 & $0.64(15)$ & $0.70(10)$ & $2.91(1)$ \\
Mali & 1231 & $47 \%(18)$ & 0.56 & 0.51 & $0.72(5)$ & $0.75(5)$ & $2.67(15)$ \\
Mozambique & 1191 & $73 \%(5)$ & 0.55 & 0.50 & $0.69(7)$ & $0.70(10)$ & $2.91(1)$ \\
Namibia & 1200 & $51 \%(16)$ & 0.55 & 0.50 & $0.69(7)$ & $0.74(7)$ & $2.67(15)$ \\
Nigeria & 2324 & $54 \%(14)$ & 0.53 & 0.47 & $0.64(15)$ & $0.68(13)$ & $2.91(1)$ \\
Senegal & 1178 & $37 \%(20)$ & 0.48 & 0.44 & $0.58(17)$ & $0.62(17)$ & $1.92(20)$ \\
South Africa & 2400 & $52 \%(15)$ & 0.53 & 0.48 & $0.65(12)$ & $0.69(12)$ & $2.67(15)$ \\
Tanzania & 1208 & $38 \%(19)$ & 0.46 & 0.41 & $0.53(20)$ & $0.54(20)$ & $2.91(1)$ \\
Uganda & 2429 & $61 \%(11)$ & 0.54 & 0.48 & $0.65(12)$ & $0.68(13)$ & $2.91(1)$ \\
Zambia & 1184 & $64 \%(10)$ & 0.53 & 0.49 & $0.65(12)$ & $0.66(15)$ & $2.91(1)$ \\
Zimbabwe & 1164 & $66 \%(8)$ & 0.55 & 0.49 & $0.68(9)$ & $0.72(9)$ & $2.91(1)$ \\
\hline
\end{tabular}

Note: In Benin, $77 \%$ of the sample is relationally deprived according to our definition of relational poverty, which ranks the country $2^{\text {nd }}$ in relational deprivation incidence. Among these relationally deprived people, the arithmetic mean of deprivations is 0.60 and the geometric mean, 0.55 .

The Utilitarian (respectively: Anonymous, Rawlsian) index defined in section 5.1.3 is 0.80

(respectively: $0.84,2.91$ ), which ranks the country first in relational deprivation intensity.

Table 11: RDI Computation

Relational poverty incidence and intensity bring complementary information. Table 11 shows that the rankings in terms of share of poor are different from those in terms of relational deprivation intensity. For example, Mali, which ranks among the least deprived countries ( $18^{\text {th }}$ position) in terms of RDI incidence, is among the poorest countries in terms of intensity ( $5^{\text {th }}$ position in intensity with anonymous weighting). In other words, relationally poor people are not very numerous in Mali (less than half of the 
sample) but the situation of these poor people is worse than the situation of poor people in other countries. An opposite example would be the case of Malawi: there are a lot of relationally poor people $\left(73 \%\right.$, which ranks the country $\left.4^{\text {th }}\right)$ but poor people are better off than in other countries (Malawi ranks $15^{\text {th }}$ in intensity with utilitarian weighting and $10^{\text {th }}$ with anonymous weighting).

The theory of justice we use as a conceptual framework has consequences on our results. We see in Table 11 that rankings are not robust to the different versions of the index - Utilitarian, Anonymous or Rawlsian - we computed. For instance, while relationally poor people are overall less deprived in Tanzania than in Senegal (the respective rankings of these countries are $20^{t h}$ and $17^{t h}$ according to the utilitarian and anonymous weightings), the most deprived person in Tanzania is relationally poorer than the most deprived person in Senegal (Tanzania ranks among the first 14 countries while Senegal ranks last in 'Rawlsian' intensity).

However, it is worth noting that some countries are robust to the different types of rankings: this is the case, for instance, of Benin, Ghana, Senegal or Lesotho. It is also worth mentioning that Rawlsian intensity scores are the same for 14 countries. A score of 2.91 corresponds to the case where the poorest person is deprived in all 4 components of the first dimension, all 3 components of the second, and 4 over 5 components of the third dimension, associated with the dimensional weight vectors $(1 / 2,1 / 4,1 / 4)$ or $(1 / 4,1 / 2,1 / 4)$. The scores of 2.67 and 2.34 also correspond to cases in which the poorest individual is fully deprived in two dimensions and has only one achievement on the last dimension (the dimension where they are not fully deprived being respectively Dim. 1 and Dim. 2). In our sample, over 20 countries, there are thus 19 countries where the poorest person has only one achievement over the 12 we used to compute RDI. The remaining country, Senegal, has a score of 1.92 which reflects two achievements over the 12 components.

Indeed, the three versions of the index that we presented in this section are just examples of coherent indices as defined in section 4. Other versions of the RDI can and should be computed, for instance, with Dirac weighting on dimensions, or with different individual weights according to socio-demographic characteristics. We aim to do so in future work, and these first results confirm the relevance of using different weights.

For comprehensibility, we only present in the following tables (Tables 12 and 13) results corresponding to the 'Anonymous' version of our index.

Our relational index adds information to the main economic development indexes. Table 12 shows that rankings for MPI and RDI differ, both in incidence, intensity and score (incidence*intensity). One should however be careful in interpreting these results, since the different indexes compared in this table were not computed the same year. Thus, our comparaisons are only indicative and additional data would be necessary to better conclude on material and relational poverty.

The examples of Mali and Lesotho reveal that material and relational deprivation are complementary. In Lesotho, there are many relationally poor people (Share of poor 


\begin{tabular}{llccccc}
\hline Country & $\begin{array}{c}\text { Share } \\
\text { of poor RDI }\end{array}$ & $\begin{array}{c}\text { Share } \\
\text { of Poor MPI }\end{array}$ & $\begin{array}{c}\text { GDP per } \\
\text { capita }\end{array}$ & $\begin{array}{c}\text { RDI } \\
\text { (Anonymous) }\end{array}$ & MPI score & RDI score \\
\hline Lesotho & $78 \%(1)$ & $35.3 \%(16)^{f}$ & 796 & 0.80 & $0.156(16)$ & $0.624(2)$ \\
Benin & $77 \%(2)$ & $71.8 \%(7)^{c}$ & 766 & 0.84 & $0.412(6)$ & $0.647(1)$ \\
Madagascar & $74 \%(3)$ & $66.9 \%(8)^{f}$ & 422 & 0.79 & $0.357(8)$ & $0.585(3)$ \\
Mozambique & $73 \%(4)$ & $79.3 \%(4)^{f}$ & 423 & 0.70 & $0.512(3)$ & $0.511(7)$ \\
Malawi & $73 \%(5)$ & $72.1 \%(6)^{a}$ & 348 & 0.70 & $0.334(9)$ & $0.505(8)$ \\
Liberia & $71 \%(6)$ & $83.9 \%(2)^{d}$ & 301 & 0.73 & $0.485(4)$ & $0.518(6)$ \\
Botswana & $70 \%(7)$ & $\mathrm{NA}$ & 5822 & 0.75 & $\mathrm{NA}$ & $0.525(5)$ \\
Zimbabwe & $66 \%(8)$ & $39.7 \%(14)^{c}$ & 492 & 0.72 & $0.172(15)$ & $0.475(9)$ \\
Burkina Faso & $65 \%(9)$ & $82.6 \%(3)^{c}$ & 522 & 0.83 & $0.535(2)$ & $0.539(4)$ \\
Zambia & $64 \%(10)$ & $64.2 \%(11)^{d}$ & 1006 & 0.66 & $0.328(11)$ & $0.422(10)$ \\
Uganda & $61 \%(11)$ & $72.3 \%(5)^{c}$ & 488 & 0.68 & $0.367(7)$ & $0.415(11)$ \\
Cape Verde & $58 \%(12)$ & $\mathrm{NA}$ & 3256 & 0.66 & $\mathrm{NA}$ & $0.383(12)$ \\
Kenya & $55 \%(13)$ & $47.8 \%(13)^{f}$ & 775 & 0.60 & $0.229(13)$ & $0.330(17)$ \\
Nigeria & $54 \%(14)$ & $54.1 \%(12)^{e}$ & 1091 & 0.68 & $0.310(12)$ & $0.367(14)$ \\
South Africa & $52 \%(15)$ & $13.4 \%(18)^{e}$ & 5738 & 0.69 & $0.057(18)$ & $0.359(15)$ \\
Namibia & $51 \%(16)$ & $39.6 \%(15)^{d}$ & 3983 & 0.74 & $0.187(14)$ & $0.377(13)$ \\
Ghana & $49 \%(17)$ & $31.2 \%(17)^{e}$ & 1090 & 0.60 & $0.144(17)$ & $0.294(18)$ \\
Mali & $47 \%(18)$ & $86.6 \%(1)^{c}$ & 601 & 0.75 & $0.558(1)$ & $0.353(16)$ \\
Tanzania & $38 \%(19)$ & $65.2 \%(10)^{e}$ & 506 & 0.54 & $0.332(10)$ & $0.205(19)$ \\
Senegal & $37 \%(20)$ & $66.9 \%(8)^{b}$ & 1055 & 0.62 & $0.439(5)$ & $0.223(20)$ \\
\hline
\end{tabular}

Rank in brackets. GDP per capita (World Bank, 2009) : current US dollars. Years of computation of the MPI are indicated by exponents: ${ }^{a} 2004 ;{ }^{b} 2005 ;{ }^{c} 2006 ;{ }^{d} 2007 ;{ }^{e} 2008 ;{ }^{f} 2009$.

Note: In Lesotho, $78 \%$ of the sample is relationally deprived according to our definition of relational poverty, which ranks the country $1^{\text {st }}$. RDI incidence is 0.80 , and RDI score (intensity*incidence) is 0.624 , which ranks the country $2^{\text {nd }}$ in relational poverty. As for material poverty, $35.3 \%$ of the inhabitants of Lesotho are materially deprived as measured by the MPI in 2009, which ranks the country $16^{\text {th }}$ in MPI incidence. MPI score is 0.156 which ranks the country $16^{\text {th }}$ in material poverty. GDP per capita is \$796.

Table 12: Ranking comparaisons

of $78 \%$ and $1^{s t}$ rank in relational deprivation incidence) and those who are deprived are very deprived, leading to the second highest RDI score of our sample; but Lesotho also has quite low MPI share of poor and score (respectively 35\% and 0.156, which ranks it $16^{\text {th }}$ among the 18 countries for which information is available). On the contrary, Mali is one of the least relationally deprived countries of our sample (it ranks $18^{\text {th }}$ in incidence and $16^{\text {th }}$ in score) but is the materially poorest country among the 18 for which MPI is available.

Though we will not detail it here, the same observation holds for RDI and GDP per capita. 


\begin{tabular}{|c|c|c|c|c|c|c|c|c|c|c|c|}
\hline \multirow{2}{*}{$\begin{array}{l}\text { RDI } \\
\text { Rank }\end{array}$} & \multirow{2}{*}{ Country } & \multirow{2}{*}{\multicolumn{2}{|c|}{$\begin{array}{l}\text { RDI Incidence } \\
\text { Score (rank) }\end{array}$}} & \multicolumn{3}{|c|}{ Poor share by dimension } & \multirow{2}{*}{\multicolumn{2}{|c|}{$\begin{array}{l}\text { RDI Intensity } \\
\text { Score (rank) }\end{array}$}} & \multicolumn{3}{|c|}{ Intensity by dimension } \\
\hline & & & & Dimension & Scor & (rank) & & & Dimension & Scol & (rank) \\
\hline 1 & Benin & $77 \%$ & $(2)$ & $\begin{array}{l}\text { Networks } \\
\text { Private relations } \\
\text { Civic engagement }\end{array}$ & $\begin{array}{l}96 \% \\
82 \% \\
97 \%\end{array}$ & $\begin{array}{l}(4) \\
(3) \\
(3)\end{array}$ & 0.84 & (1) & $\begin{array}{l}\text { Networks } \\
\text { Private relations } \\
\text { Civic engagement }\end{array}$ & $\begin{array}{l}0.42 \\
0.33 \\
0.44\end{array}$ & $\begin{array}{l}(8) \\
(1) \\
(7)\end{array}$ \\
\hline 2 & Lesotho & $78 \%$ & $(1)$ & $\begin{array}{l}\text { Networks } \\
\text { Private relations } \\
\text { Civic engagement }\end{array}$ & $\begin{array}{l}97 \% \\
84 \% \\
94 \%\end{array}$ & $\begin{array}{l}(1) \\
(2) \\
(12)\end{array}$ & 0.80 & (3) & $\begin{array}{l}\text { Networks } \\
\text { Private relations } \\
\text { Civic engagement }\end{array}$ & $\begin{array}{l}0.35 \\
0.40 \\
0.47\end{array}$ & $\begin{array}{l}(5) \\
(5) \\
(12)\end{array}$ \\
\hline 3 & Madagascar & $74 \%$ & (3) & $\begin{array}{l}\text { Networks } \\
\text { Private relations } \\
\text { Civic engagement }\end{array}$ & $\begin{array}{l}87 \% \\
87 \% \\
99 \%\end{array}$ & $\begin{array}{l}(12) \\
(1) \\
(1)\end{array}$ & 0.79 & $(4)$ & $\begin{array}{l}\text { Networks } \\
\text { Private relations } \\
\text { Civic engagement }\end{array}$ & $\begin{array}{l}0.43 \\
0.42 \\
0.40\end{array}$ & $\begin{array}{l}(9) \\
(6) \\
(4)\end{array}$ \\
\hline 4 & Burkina Faso & $65 \%$ & $(9)$ & $\begin{array}{l}\text { Networks } \\
\text { Private relations } \\
\text { Civic engagement }\end{array}$ & $\begin{array}{l}96 \% \\
69 \% \\
97 \%\end{array}$ & $\begin{array}{l}(5) \\
(15) \\
(4)\end{array}$ & 0.83 & $(2)$ & $\begin{array}{l}\text { Networks } \\
\text { Private relations } \\
\text { Civic engagement }\end{array}$ & $\begin{array}{l}0.35 \\
0.47 \\
0.44\end{array}$ & $\begin{array}{l}(4) \\
(11) \\
(9)\end{array}$ \\
\hline 5 & Botswana & $70 \%$ & $(7)$ & $\begin{array}{l}\text { Networks } \\
\text { Private relations } \\
\text { Civic engagement }\end{array}$ & $\begin{array}{l}87 \% \\
81 \% \\
96 \%\end{array}$ & $\begin{array}{l}(11) \\
(4) \\
(6)\end{array}$ & 0.75 & $(5)$ & $\begin{array}{l}\text { Networks } \\
\text { Private relations } \\
\text { Civic engagement }\end{array}$ & $\begin{array}{l}0.50 \\
0.37 \\
0.45\end{array}$ & $\begin{array}{l}(12) \\
(2) \\
(11)\end{array}$ \\
\hline 6 & Liberia & $71 \%$ & $(6)$ & $\begin{array}{l}\text { Networks } \\
\text { Private relations } \\
\text { Civic engagement }\end{array}$ & $\begin{array}{l}96 \% \\
77 \% \\
91 \% \\
\end{array}$ & $\begin{array}{l}(6) \\
(9) \\
(15)\end{array}$ & 0.73 & $(8)$ & $\begin{array}{l}\text { Networks } \\
\text { Private relations } \\
\text { Civic engagement }\end{array}$ & $\begin{array}{l}0.34 \\
0.46 \\
0.56\end{array}$ & $\begin{array}{l}(1) \\
(10) \\
(18)\end{array}$ \\
\hline 7 & Mozambique & $73 \%$ & $(5)$ & $\begin{array}{l}\text { Networks } \\
\text { Private relations } \\
\text { Civic engagement }\end{array}$ & $\begin{array}{l}92 \% \\
81 \% \\
96 \%\end{array}$ & $\begin{array}{l}(9) \\
(6) \\
(8)\end{array}$ & 0.70 & (11) & $\begin{array}{l}\text { Networks } \\
\text { Private relations } \\
\text { Civic engagement }\end{array}$ & $\begin{array}{l}0.41 \\
0.50 \\
0.44\end{array}$ & $\begin{array}{l}(7) \\
(16) \\
(10)\end{array}$ \\
\hline 8 & Malawi & $73 \%$ & $(4)$ & $\begin{array}{l}\text { Networks } \\
\text { Private relations } \\
\text { Civic engagement }\end{array}$ & $\begin{array}{l}97 \% \\
81 \% \\
91 \%\end{array}$ & $\begin{array}{l}(2) \\
(5) \\
(16)\end{array}$ & 0.70 & $(10)$ & $\begin{array}{l}\text { Networks } \\
\text { Private relations } \\
\text { Civic engagement }\end{array}$ & $\begin{array}{l}0.34 \\
0.52 \\
0.55\end{array}$ & $\begin{array}{l}(2) \\
(17) \\
(17)\end{array}$ \\
\hline 9 & Zimbabwe & $66 \%$ & (8) & $\begin{array}{l}\text { Networks } \\
\text { Private relations } \\
\text { Civic engagement }\end{array}$ & $\begin{array}{l}93 \% \\
75 \% \\
96 \%\end{array}$ & $\begin{array}{l}(8) \\
(12) \\
(10)\end{array}$ & 0.72 & (9) & $\begin{array}{l}\text { Networks } \\
\text { Private relations } \\
\text { Civic engagement }\end{array}$ & $\begin{array}{l}0.34 \\
0.49 \\
0.52\end{array}$ & $\begin{array}{l}(3) \\
(14) \\
(15)\end{array}$ \\
\hline 10 & Zambia & $64 \%$ & $(10)$ & $\begin{array}{l}\text { Networks } \\
\text { Private relations } \\
\text { Civic engagement }\end{array}$ & $\begin{array}{l}91 \% \\
76 \% \\
91 \%\end{array}$ & $\begin{array}{l}(10) \\
(11) \\
(17)\end{array}$ & 0.66 & $(16)$ & $\begin{array}{l}\text { Networks } \\
\text { Private relations } \\
\text { Civic engagement }\end{array}$ & $\begin{array}{l}0.43 \\
0.48 \\
0.50\end{array}$ & $\begin{array}{l}(10) \\
(13) \\
(14)\end{array}$ \\
\hline 11 & Uganda & $61 \%$ & $(11)$ & $\begin{array}{l}\text { Networks } \\
\text { Private relations } \\
\text { Civic engagement }\end{array}$ & $\begin{array}{l}85 \% \\
77 \% \\
92 \%\end{array}$ & $\begin{array}{l}(15) \\
(10) \\
(14)\end{array}$ & 0.68 & $(14)$ & $\begin{array}{l}\text { Networks } \\
\text { Private relations } \\
\text { Civic engagement }\end{array}$ & $\begin{array}{l}0.49 \\
0.42 \\
0.48\end{array}$ & $\begin{array}{l}(11) \\
(7) \\
(13)\end{array}$ \\
\hline 12 & Cape Verde & $58 \%$ & $(12)$ & $\begin{array}{l}\text { Networks } \\
\text { Private relations } \\
\text { Civic engagement }\end{array}$ & $\begin{array}{l}76 \% \\
74 \% \\
98 \%\end{array}$ & $\begin{array}{l}(18) \\
(13) \\
(2)\end{array}$ & 0.66 & $(15)$ & $\begin{array}{l}\text { Networks } \\
\text { Private relations } \\
\text { Civic engagement }\end{array}$ & $\begin{array}{l}0.56 \\
0.50 \\
0.33\end{array}$ & $\begin{array}{l}(18) \\
(15) \\
(1)\end{array}$ \\
\hline 13 & Namibia & $51 \%$ & $(16)$ & $\begin{array}{l}\text { Networks } \\
\text { Private relations } \\
\text { Civic engagement }\end{array}$ & $\begin{array}{l}84 \% \\
60 \% \\
97 \%\end{array}$ & $\begin{array}{l}(16) \\
(17) \\
(5)\end{array}$ & 0.74 & $(7)$ & $\begin{array}{l}\text { Networks } \\
\text { Private relations } \\
\text { Civic engagement }\end{array}$ & $\begin{array}{l}0.52 \\
0.47 \\
0.35\end{array}$ & $\begin{array}{l}(14) \\
(12) \\
(2)\end{array}$ \\
\hline 14 & Nigeria & $54 \%$ & $(14)$ & $\begin{array}{l}\text { Networks } \\
\text { Private relations } \\
\text { Civic engagement }\end{array}$ & $\begin{array}{l}73 \% \\
78 \% \\
95 \%\end{array}$ & $\begin{array}{l}(19) \\
(8) \\
(11)\end{array}$ & 0.68 & $(13)$ & $\begin{array}{l}\text { Networks } \\
\text { Private relations } \\
\text { Civic engagement }\end{array}$ & $\begin{array}{l}0.59 \\
0.39 \\
0.44\end{array}$ & $\begin{array}{l}(19) \\
(3) \\
(8)\end{array}$ \\
\hline 15 & South Africa & $52 \%$ & $(15)$ & $\begin{array}{l}\text { Networks } \\
\text { Private relations } \\
\text { Civic engagement }\end{array}$ & $\begin{array}{l}68 \% \\
79 \% \\
96 \%\end{array}$ & $\begin{array}{l}(20) \\
(7) \\
(9)\end{array}$ & 0.69 & $(12)$ & $\begin{array}{l}\text { Networks } \\
\text { Private relations } \\
\text { Civic engagement }\end{array}$ & $\begin{array}{l}0.61 \\
0.39 \\
0.40\end{array}$ & $\begin{array}{l}(20) \\
(4) \\
(3)\end{array}$ \\
\hline 16 & Mali & $47 \%$ & $(18)$ & $\begin{array}{l}\text { Networks } \\
\text { Private relations } \\
\text { Civic engagement }\end{array}$ & $\begin{array}{l}97 \% \\
50 \% \\
96 \% \\
\end{array}$ & $\begin{array}{l}(3) \\
(19) \\
(7)\end{array}$ & 0.75 & $(6)$ & $\begin{array}{l}\text { Networks } \\
\text { Private relations } \\
\text { Civic engagement }\end{array}$ & $\begin{array}{l}0.36 \\
0.52 \\
0.43 \\
\end{array}$ & $\begin{array}{l}(6) \\
(18) \\
(6)\end{array}$ \\
\hline 17 & Kenya & $55 \%$ & (13) & $\begin{array}{l}\text { Networks } \\
\text { Private relations } \\
\text { Civic engagement }\end{array}$ & $\begin{array}{l}85 \% \\
71 \% \\
87 \%\end{array}$ & $\begin{array}{l}(13) \\
(14) \\
(18)\end{array}$ & 0.60 & (19) & $\begin{array}{l}\text { Networks } \\
\text { Private relations } \\
\text { Civic engagement }\end{array}$ & $\begin{array}{l}0.54 \\
0.43 \\
0.57\end{array}$ & $\begin{array}{l}(15) \\
(8) \\
(19)\end{array}$ \\
\hline 18 & Ghana & $49 \%$ & $(17)$ & $\begin{array}{l}\text { Networks } \\
\text { Private relations } \\
\text { Civic engagement }\end{array}$ & $\begin{array}{l}82 \% \\
69 \% \\
86 \%\end{array}$ & $\begin{array}{l}(17) \\
(16) \\
(19)\end{array}$ & 0.60 & $(18)$ & $\begin{array}{l}\text { Networks } \\
\text { Private relations } \\
\text { Civic engagement }\end{array}$ & $\begin{array}{l}0.55 \\
0.46 \\
0.54\end{array}$ & $\begin{array}{l}(17) \\
(9) \\
(16)\end{array}$ \\
\hline 19 & Tanzania & $38 \%$ & (19) & $\begin{array}{l}\text { Networks } \\
\text { Private relations } \\
\text { Civic engagement }\end{array}$ & $\begin{array}{l}85 \% \\
52 \% \\
81 \%\end{array}$ & $\begin{array}{l}(14) \\
(18) \\
(20)\end{array}$ & 0.54 & $(20)$ & $\begin{array}{l}\text { Networks } \\
\text { Private relations } \\
\text { Civic engagement }\end{array}$ & $\begin{array}{l}0.50 \\
0.54 \\
0.59\end{array}$ & $\begin{array}{l}(13) \\
(19) \\
(20)\end{array}$ \\
\hline 20 & Senegal & $37 \%$ & $(20)$ & $\begin{array}{l}\text { Networks } \\
\text { Private relations } \\
\text { Civic engagement }\end{array}$ & $\begin{array}{l}93 \% \\
41 \% \\
92 \%\end{array}$ & $\begin{array}{l}(7) \\
(20) \\
(13)\end{array}$ & 0.62 & $(17)$ & $\begin{array}{l}\text { Networks } \\
\text { Private relations } \\
\text { Civic engagement }\end{array}$ & $\begin{array}{l}0.54 \\
0.59 \\
0.42\end{array}$ & $\begin{array}{l}(16) \\
(20) \\
(5)\end{array}$ \\
\hline
\end{tabular}

RDI Rank and Intensity are computed using 'Anonymous' rankings.

Note: In Benin, $77 \%$ of the sample is relationally deprived according to our definition of relational poverty, which ranks the country $2^{\text {nd }}$ in relational deprivation incidence. 96\% (82\%, 97\%) of the sample is deprived in dim. 1 (respectively: 2, 3 ) which ranks Benin $4^{\text {th }}\left(3^{\text {rd }}\right)$ in the proportion of people deprived in dim. 1 (respectively: 2, 3).

Among the $77 \%$ of relationally deprived people, the intensity of relational deprivations (using anonymous weightings) is 0.84 which ranks the country $1^{\text {st }}$, the intensity of deprivations in dim. 1 (respectively: 2, 3) is 0.42 (respectively: 0.33, 0.44) which ranks the country $8^{\text {th }}$ (respectively: $1^{\text {st }}, 7^{\text {th }}$ ).

Table 13: Rank comparaisons by dimensions 
Our three dimensions play a different role in the determination of the scores and rankings. Table 13 details the incidence and intensity of relational deprivation at the dimension level. Poor shares by dimension represent the proportion of people who have a relational score under the dimensional threshold (equal to 1 in this paper), for a given dimension. As a reminder, someone is considered as relationally non-deprived if he is not deprived in any of our three dimensions. Intensity by dimension represent the average score in each dimension among the people who are deprived for RDI (and not just in the corresponding dimension).

The results show that whereas more people are deprived in the first and the third dimensions (respectively: integration into networks and civic engagement) than in the second one (private relations), there is no significant difference -in terms of both mean and standard deviation - in the countries' intensity of relational deprivation between the three dimensions.

Though detailed comments about the global and dimensional scores by country will not be provided in this paper, they should be an object of further research.

\subsubsection{Interpretation regarding Englebert's concept of State Legitimacy}

Focusing on political economy of African countries sheds particular light on our results. Trust in institutions is expected to impact directly "trust in others", one component of the "civic commitment" dimension. Moreover, it might also have an indirect influence on other components, such as trust in the community, membership and collective action. Englebert (2000) stresses the relationship between state as a structure and society as a whole of individuals through the concept of state legitimacy (see Bratton and Chang (2006) for a review). State legitimacy is "a structural variable determined by history: a state is deemed legitimate when it has evolved endogenously to local social relations of power and authority or when, having originally been imported, it is then absorbed by such preexisting endogenous institutions." (Englebert, 2000, p.72). Empirically, two key dimensions define legitimacy. Vertical legitimacy refers to the endogeneity of state and society. Indeed, state in Africa is often inherited from the colonization period. When appropriated by new elite, it is more or less consistent with a background of preexisting institutions ${ }^{23}$. Horizontal legitimacy is defined as the ethnic fragmentation inside the country, i.e. an index of the consistency of borders definition, or the extent to which there is agreement about what constitutes the polity or the community that comprises the state.

African legitimate states are better leviathans, enforce property rights, have better institutions. Consequently, they are trusted by their citizens. Hence, we expect a positive correlation between state legitimacy and relational capability, such as an absolute value close to 1. Empirically, we obtain mitigated results, with a Spearman's rank correlation coefficient (rho) of 0.47 significant at a $95 \%$ level between horizontal legitimacy and RDI score. The Spearman rho between vertical legitimacy and RDI score is 0.41 , significant

\footnotetext{
${ }^{23}$ States that are endogenous to societies are Ethiopia, Cape Verde, Mauritius, Seychelles, Sao Tomé and Principe, Swaziland and Lesotho, Botswana and to a less extent Rwanda and Burundi
} 
at $90 \%$. For instance, the correlation is high for Benin, where RDI score is 0.647 and which has a low state legitimacy : the state is not vertically legitimate, and its horizontal legitimacy score is only $67 \%$, below the lower bound of $75 \%$. However, the discrepancy between the two indicators is remarkable. As an example, Botswana is a vertical legitimate state, and has a $90.53 \%$ horizontal legitimacy. However, its 0.525 RDI score is one of the largest of the sample, i.e. its deprivation rate is high. Further investigation is required to assess the link between state legitimacy and relational capacity. 


\section{References}

Acket, S., Borsenberger, M., Dickes, P., and Sarracino, F. (2011). Measuring and validating social cohesion: a bottom-up approach. Working Paper 2011-08, CEPS/INSTEAD, Luxembourg. 13

Alkire, S. (2002). Valuing freedoms: Sen's capability approach and poverty reduction (2005). Oxford University Press, Oxford, UK. 15

Alkire, S. and Foster, J. (2008). Counting and multidimensional poverty measurement. OPHI Working Paper. 2, 12, 21, 22, 32, 35

Alkire, S. and Santos, E. (2010). Acute multidimensional poverty: A new index for developing countries. Technical Report 38, OPHI, Oxford University. 2, 14, 18, 43

Alkire, S. and Seth, S. (2008). Measuring multidimensional poverty in india: a new proposal. OPHI working paper. 12

Aristotle (350BC). The Nicomachean Ethics. Oxford University Press. Translation by D. Ross (1925), Oxford, UK. 9

Artzner, P., Delbaen, F., Ebera, J.-M., and Heath, D. (1999). Coherent measures of risk. Mathematical Finance, 9(3):203-228. 22, 28

Atkinson, A. B., Cantillon, B., Marlier, E., and Nolan, B. (2002). Social indicators: the EU and social inclusion. Oxford University Press. 2002514394. 18

Batana, Y. M. (2008). Multidimensional measurement of poverty in sub-saharian africa. Technical report, OPHI working paper. 12

Bentham, J. (1815). A table of the springs of action (edition 1983). Four early works on motivation, pages $477-512$. 7

Bernard, P. (1999). Social cohesion: A critique. Canadian Policy Research Networks. 5. 11, 13

Boltanski, L. and Chiapello, E. (1999). The New Spirit of Capitalism. Verso, London/New York. 14

Bossert, W., Chakravarty, S. R., and D'Ambrosio, C. (2009). Multidimensional poverty and material deprivation. Technical report, Université de Montréal, Département de sciences économiques, Montreal, Canada. 17

Bourdieu, P. (1994). Raisons pratiques: sur la théorie de l'action. Seuil. 4

Bourguignon, F. and Chakravarty, S. R. (2003). The measurement of multidimensional poverty. Journal of Economic Inequality, 1:25-49. 21,22 
Bratton, M. and Chang, E. (2006). State building and democratization in sub-saharan africa: Forward, backwards, or together? Comparative Political Studies, 39:1059-1083. 48

Burt, R. (1992). Structural Holes: The Social Structure of Competition. Harvard University Press. 10

Burt, R. S. (1997). The contingent value of social capital. Administrative Science Quarterly, 42(2):339-365. 10

Chakravarty, S. R. (2009). Inequality, Polarization and Poverty. Advances in Distributional Analysis. Springer, New York. 21

Chakravarty, S. R. and D'Ambrosio, C. (2006). The measurement of social exclusion. Review of Income and Wealth, 52(3):377-398. 18

Chan, J., To, H.-P., and Chan, E. (2006). Reconsidering social cohesion: Developing a definition and analytical framework for empirical research. Social Indicators Research, 75(2):273-302. 13

Coleman, J. (1990). Foundations of social theory. Belknap Press. 4

Coleman, J. S. (1988). Social capital in the creation of human capital. American Journal of Sociology, 94:95-120. 4, 10, 14

Dardadoni, V. (1995). On multidimensional poverty measurement. Research on Economic Inequality, 6:201-207. 21

De Munck, J. and Zimmermann, B. (2008). La liberté au prisme des capacités. Amartya Sen au-delà du libéralisme. Raisons pratiques. Editions de l'Ecole des Hautes Etudes en Sciences Sociales, Paris. 2

Dhillon, A. and J.-F. Mertens, J.-F. (1999). Relative utilitarianism. Econometrica, 67:471-498. 21

Dickes, P., Valentova, M., and Borsenberger, M. (2010). Construct validation and application of a common measure of social cohesion in 33 european countries. Social Indicators Research, 98(3):451-473. 13

Dreze, J. and Sen, A. (2002). India: Development and participation. Oxford University Press, USA. 8

Ellickson, B., Grodal, B., Scotchmer, S., and Zame, W. (1999). Clubs and the market. Econometrica, 67(5). 4

Ellickson, B., Grodal, B., Scotchmer, S., and Zame, W. R. (2001). Clubs and the market: Large finite economies. Journal of Economic Theory, 101(1):40-77. 4 
Englebert, P. (2000). State legitimacy and development in Africa. Boulder, Colo. : Lynne Rienner Publishers. 48

\{Eurostat\} (2003). Laeken indicators - detailed calculation methodology. Technical Report DOC. E2/IPSE/2003, European Comission. 18

Fleurbaey, M. and Maniquet, F. (2008). Fair social orderings. Economic Theory, $34(1): 25-45.21$

Foa, R. and Tanner, J. C. (2011). Methodology of the indices of social development. ISS working paper series, International Institute of Social Studies, The Haag. 13

Fraser, N. (2009). Scales of Justice: Reimagining Political Space in a Globalizing World. Columbia University Press, New York. 11

George, W. W. (2003). Authentic Leadership: Rediscovering the Secrets to Creating Lasting Value. Jossey-Bass. 15

Giraud, G. and Renouard, C. (2012). Le Facteur 12: Pourquoi il faut plafonner les revenus. Carnets Nord, Paris, France. 6

Granovetter, M. (1985). Economic action and social structure: the problem of embeddedness. American journal of sociology, pages 481-510. 10

Huber, P. (1981). Robust Statistics. Wiley, New York. 30

ICPSR (2008-2009). Afrobarometer round 4: The quality of democracy and governance in 20 African countries. 43

Jackson, M. and Wolinsky, A. (1996). A strategic model of social and economic networks. New York: Academic Press., 71(1). 14

Jany-Catrice, F. (2009). The french regions and their social health. Social indicators research, 93(2):377-391. 19, 20

Kant, I. (1785). Grounding for the Metaphysics of Morals: With, On a Supposed Right to Lie Because of Philanthropic Concerns. Hackett Publishing (1993). 8

Krishnakumar, J. and Nagar, A. L. (2008). On exact statistical properties of multidimensional indices based on principal components, factor analysis, MIMIC and structural equation models. Social Indicators Research, Volume 86(3):481-496. 13

Kuehnast, K. and Dudwick, N. (2004). Better a hundred friends than a hundred rubles: social networks in transition -the kyrgyz republic. World Bank Working Paper 39, World Bank, Washington, DC. 6

Lugo, M. A. and Maasoumi, E. (2008). Multidimensional poverty measures from an information theory perspective. Ecineq working paper, 41:68-85. 21 
Marlier, E. (2007). The EU and social inclusion: facing the challenges. Policy. 2007273337. 18

Marlier, E. and Atkinson, A. B. (2010). Indicators of poverty and social exclusion in a global context. Journal of Policy Analysis and Management, 29(2):285-304. 3

Mill, J. S. (1861). Utilitarianism. Everyman Library, London (1992). 7, 8

Nussbaum, M. (2000). Women and human development: the capabilities approach. Cambridge University Press, Cambridge, UK. 7, 9, 12, 14

Nussbaum, M. (2002). Capabilities and social justice. International Studies Review, 4:123-135. 9

Nussbaum, M. (2003). Capabilities as fundamental entitlements: Sen and social justice. Feminist Economics, 9(2-3):33-59. 2, 15

Paugham, S. and Russell, H. (2000). The effects of employment precarity and unemployment on social isolation. In Gallie, D. and Paugham, S., editors, Welfare Regimes and the Experience of Unemployment in Europe. Oxford University Press, Oxford, UK. 14

Polanyi, K. (1957). The great transformation. Beacon Press. 5

Porter, D. and Craig, D. (2004). The third way and the third world: poverty reduction and social inclusion in the rise of 'inclusive' liberalism. Review of International Political Economy, 11(2):387-423. 5

Ravallion, M. (1996). Issues in measuring and modelling poverty. Economic Journal, 106:1328-1343. 21]

Rawls, J. (1971). A Theory of Justice. Harvard University Press, Cambridge, Massachusetts. 6, 12, 18,21

Ray, A. K. (2008). Measurement of social development: an international comparison. Social Indicators Research, 86(1):1-46. 14

Renouard, C. (2011). Corporate social responsibility, utilitarianism, and the capabilities approach. Journal of Business Ethics, 98(1):85-97. 10.1007/s10551-010-0536-8. 7

Ricœur, P. (1990). Oneself As Another. Paperback. 15

Robeyns, I. (2005). The capability approach: a theoretical survey. Journal of Human Development, 6(1):93-117. 8

Santos, M. E. and Ura, K. (2008). Multidimensional poverty in Bhutan: Estimates and policy implications. Oxford Poverty \& Human Development Initiative. 12

Sen, A. (1999). Development as freedom. Oxford University Press, Oxford, UK. 2, 5,8 
Seth, S. (2009). A class of association sensitive multidimensional welfare indices. Journal of Economic Inequality (forthcoming). 23

Tsui, K. (1996). Multidimensional poverty indices. Social Choice and Welfare, 19:69-93. 21

UNDP (1990). Concept and measurement of human development. Human development report, United Nations Development Programme. 2

UNDP (2010). The real wealth of nations: Pathways to human development. Human development report, United Nations Development Programme. 2, 18

UNDP Europe \& CIS (2011). Beyond transition towards more inclusive societies. Regional human development report, United Nations Development Programme, Regional Bureau for Europe and CIS., Bratislava. 12, 19, 20

United Nations (1995). Report of the world summit for social development, copenhagen, 6-12 march 1995. Technical Report Sales No. E. 96.IV.8., United Nations. 3

Villar, A. (2010). A new approach to multidimensional poverty measurement. Pablo Olavide university Working Paper. 21, 22, 23, 25, 32, 33

Wagle, U. (2008). Multidimensional Poverty Measurements. Concepts and Applications. New York, Springer. 21

Walzer, M. (1983). Spheres Of Justice: A Defense Of Pluralism And Equality. Basic Books, New York. 11, 13, 15, 17, 34

Walzer, M. (1994). Thick and Thin: Moral Argument at Home and Abroad. University Notre-Dame Press, Notre-Dame. 12

Wilkinson, R. and Pickett, K. (2009). The Spirit Level: Why Equality is Better for Everyone. Penguin Books Limited. 6

Young, I. M. (2000). Inclusion and Democracy. Oxford University Press. 8 